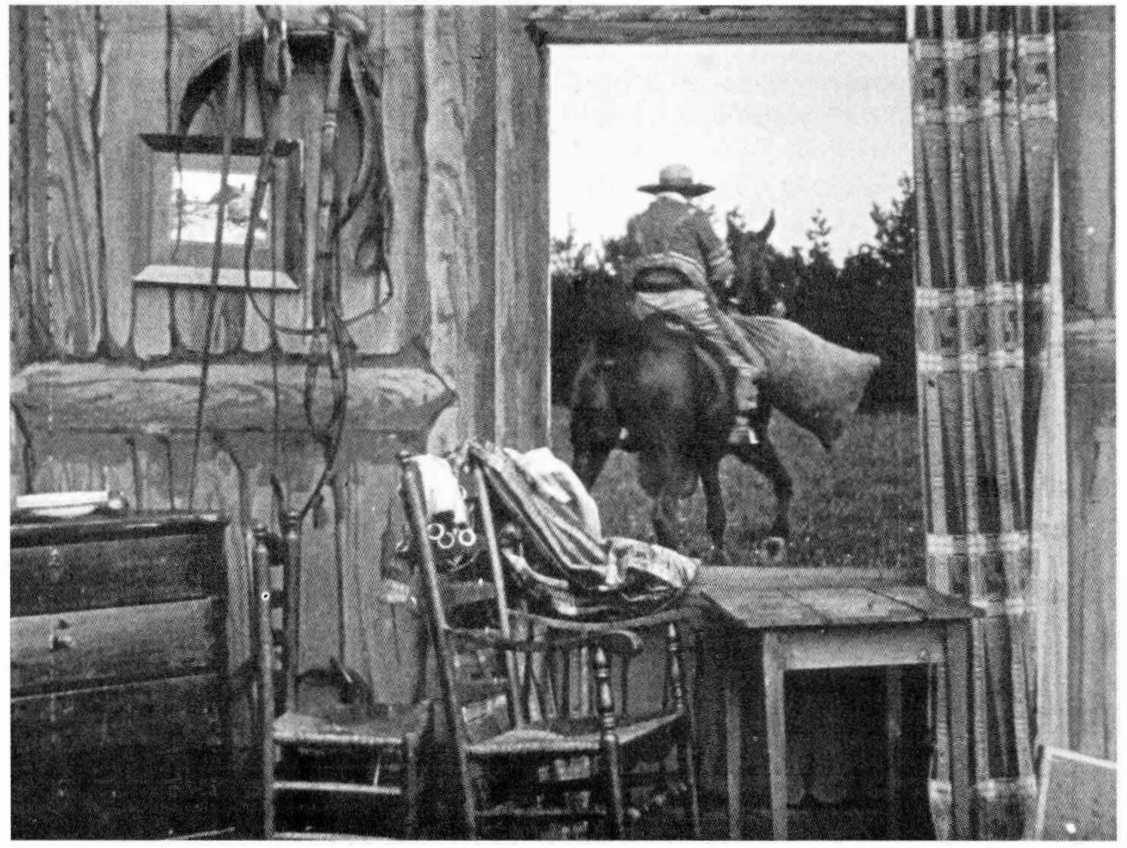




\title{
La construcción de una agrociudad en el noroeste de México. Ciudad Obregón (1925-1960)*
}

\author{
Mario Cerutti**
}

$\mathrm{E}$ ste trabajo inicial sobre Ciudad Obregón y su entorno productivo ${ }^{1}$ procurará describir las condiciones que hicieron nacer y transformaron a esta urbe -entre los años veinte y la década de

* Con la colaboración de Marcela Preciado Nava.

** Profesor-investigador de la Universidad Autónoma de Nuevo León. Miembro del Sistema Nacional de Investigadores (nivel III). Especializado en la historia económica y empresarial del norte de México, ha publicado resultados de investigación en Alemania, Italia, Holanda, España, Portugal, Inglaterra, Suecia, Estados Unidos, Argentina, Brasil, Colombia, Venezuela, Uruguay y México. Entre sus libros destacan: Propietarios, empresarios y empresa en el norte de México, Siglo XXI, México, 2000; Del mercado protegido al mercado global. Monterrey (1925-2000), Trillas, México, 2003; Empresarios españoles y sociedad capitalista en México, 1840-1920, Fundación Archivo de Indianos, Colombres (España), 1995; Burguesia, capitales e industria en el norte de México. Monterrey y su ámbito regional, 1850-1910, Alianza Editorial/Universidad Autónoma de Nuevo León, México, 1992. Coautor: con Menno Vellinga, Burguestas e industria en América Latina y Europa meridional, Alianza Editorial, Madrid, 1989; con Carlos Marichal, Historia de las grandes empresas en México, FCE/Universidad Autónoma de Nuevo León, México, 1997; con Miguel González Quiroga, Frontera e Historia Económica, Instituto Mora, México, 1993; con Carlos Marichal, La banca regional en México (1870-1920), FCE, México, 2003.

${ }^{1}$ Primer resultado del proyecto "Empresa y agricultura de exportación en el noroeste de México. His- los sesenta del siglo Xx-en eje de referencia y funcionamiento para un muy dinámico espacio agrícola del noroeste de México, de un ámbito que incluye el sur de Sonora y el norte de Sinaloa. Para una interpretación más adecuada de este proceso regional habremos de utilizar un par de conceptos muy instrumentales, heredados de la más reciente literatura sobre la Europa del sur: sistema productivo local y agrociudad.

El texto se concentrará en: $a$ ) brindar una sucinta referencia sobre ambas nociones; b) ubicar históricamente y delinear el territorio (o el espacio regional) que anidó el surgimiento de la principal urbe que existe hoy entre Hermosillo y Culiacán; c) practicar una reseña de la agricultura en ese territorio en el periodo de 1925$1960 ; d)$ situar en ese contexto al valle del Yaqui, sus sistemas de irrigación y los mecanismos de explotación de la tierra que se desenvolvieron en el periodo; $e$ ) sintetizar y cuantificar la natalidad empresarial en Ciudad Obregón a partir de los años veinte; $f$ ) dibujar su desarrollo como eje urbano regional.

toria económica y tendencias actuales", respaldado por CONACYT y compartido entre las universidades Autónoma de Sinaloa (UAS), Nacional Autónoma de México (UNAM), de Sonora (UNISON) y Autónoma de Nuevo León (UANL). 


\section{UN PAR DE CONCEPTOS}

El estudio de los distritos industriales italianos alentó en la Europa del sur numerosos proyectos de investigación y una amplia literatura que, poco a poco, fue encontrando ágiles nichos de desenvolvimiento en España, Francia y Portugal.

En la medida en que se fue profundizando sobre esta temática sucedieron tres fenómenos: a) el debate salió del ámbito específico de los distritos industriales italianos, alcanzó otras regiones europeas y aterrizó parcialmente en América; $b$ ) se multiplicaron las denominaciones o las variantes conceptuales en la misma medida en que, según Denis Maillat, resultaban instrumentales para analizar formas de organizar la producción a escala local, territorial o regional: distrito industrial, sistemas localizados de producción e innovación, sistemas productivos por áreas, tejido industrial local, tejido empresarial, sistema industrial localizado, sistema productivo local, sistema local de empresas, ecosistemas localizados, mesosistema productivo, sistema de producción e innovación localizado, distrito tecnológico; ${ }^{2} c$ ) se traspasó la actividad puramente industrial/urbana para ocuparse del conjunto de actividades económicas o de la economía difusa ${ }^{3}$ de un territorio determinado.

$\mathrm{Al}$ avanzar hacia el análisis de áreas donde hubo o hay predominio histórico de la agricultura, Silvia Gorenstein destacó que la noción "sistemas localès de producción" suscitó "un gran interés analítico por sus potencialidades para interpretar

2 Maillat, "Sistemas", 1996, p. 77.

${ }^{3} \mathrm{El}$ concepto economía difusa en Bagnasco, "Nacimiento", 2000. los cambios en los espacios rurales y, más específicamente, los factores que inciden en los vínculos entre el medio rural y el urbano". Y dentro de este esquema, prosiguió Gorenstein, numerosos estudios han examinado "las interdependencias rutal-urbanas" y "los eslabonamientos (hacia atrás y hacia adelante) inducidos por la articulación de la agricultura con la agroindustria y los servicios". ${ }^{4}$

En este sentido, la aparición de asentamientos urbanos que acentúen o multipliquen la división del trabajo (por ejemplo, con instalaciones agroindustriales) u operen como prestadores de servicios diversos, "beneficia el desarrollo agrícola", intensifica la agriculturización del territorio bajo estudio, fertiliza la capacidad de engendrar empresas y fortalece el tejido empresarial.

Estaría naciendo, allí, la agrociudad. Es decir, un tipo específico de urbe gestado por un contexto de pujante dinámica agrícola, con elevada fertilidad empresarial, y que sustentada en una localización adecuada, una infraestructura funcional y en instituciones que maduran en su favor, es históricamente capaz de: a) tornarse punto de referencia significativo para la administración y la atención del espacio agrícola que la rodea; $b$ ) ser la proveedora estratégica de un conjunto de servicios indispensables (almacenamiento, mantenimiento, diversiones, educación, seguridad, crédito, salud, contactos sociales); c) concentrar buena parte de la transformación industrial de las materias primas cosechadas en su entorno rural; $d$ ) convertirse en hegemónica o preponderante dentro de un sis-

\footnotetext{
${ }^{4}$ Gorenstein, "Rasgos", 2001, pp. 46-47.

sIbid, p. 49.
} 
tema de ciudades pequeñas y medianas que crecen en el mismo territorio. ${ }^{6}$

Ciudad Obregón, nacida en 1927 bajo el nombre de Ciudad Cajeme, representaría en este sentido uno de los más notables casos de agrociudad en el México del siglo Xx. Y como sucedió con la muy ágil Torreón porfiriana, entre los más llamativos datos de su aparición y desarrollo estarían: a) operar en un espacio regional biestatal; b) nacer en un medio geográfico semiárido y de difícil manejo para los seres humanos; $c$ ) ser fruto complementario de grandes obras de irrigación; $d$ ) atraer una densa inmigración nacional y extranjera; e) convertirse en poco más de 30 años en una ciudad competidora con la capital estatal; $f$ ) acoger uno de los más llamativos nichos de desarrollo empresarial en el norte de México. ${ }^{7}$

\section{EL TERRITORIO}

El espacio a adoptar como escenario en el noroeste (véase mapa 1) es jurídicamente biestatal. Se lo indagará bajo una perspectiva que puntualiza y se apoya en la homogeneidad del objeto de estudio. Las razones para adoptar ese enfoque comprendieron desde las sustentadas en la historia económico empresarial hasta las li-

${ }^{6}$ Referencias y discusiones sobre la noción agrociudad pueden encontrarse en López, "Agrociudad", 1994, quien además de enumerar una amplia bibliografía sobre el tema destaca, entre otras caracrerísticas, "la mezcla inextricable en su estructura de rasgos urbanos y rurales" que presenta este tipo de ciudad ( $p$. 65).

7 Sobre la aparición de bolsones de desarrollo empresarial en el norte de México entre 1850 y 2000 , Cerutti, "Fertilidad", 2004; "Redes", 2005. gadas a los recursos naturales o de cómo vieron en su momento este rincón de México algunos de los principales protagonistas de su desarrollo.

El conjunto territorial agrupa en la actualidad doce municipios, de los cuales nueve se encuentran en Sonora. Su superficie (véase cuadro 1) alcanza 15\% de la que ocupan ambos estados, mientras que su población, según cifras recientes, supera $33 \%$ de la que suman Sonora y Sinaloa (cuadro 2). O sea, la densidad por $\mathrm{km}^{2}$ es mayor a la del conjunto biestatal, lo cual indica factores de atracción demográfica ligados a una actividad económica más vigorosa o con mayores oportunidades.

En términos de uno de sus recursos fundamentales -el agua-, este espacio regional es abastecido por cuatro importantes ríos, todos provenientes de la Sierra Madre Occidental: Yaqui, Mayo, Fuerte y Sinaloa. Sobre ellos, o a partir de ellos, fueron apareciendo desde los años treinta algunas de las más monumentales presas del norte de México: La Angostura, Oviachic y El Novillo (río Yaqui); Mocúzari (río Mayo); Miguel Hidalgo y Josefa Ortiz (río Fuerte); y Bacurato (río Sinaloa).

Estas presas y sus sistemas de irrigación -montados en gran medida por medio de enormes inversiones federales ${ }^{8}$ posibilitaron la explotación agrícola de centenares de miles de hectáreas. Una muy importante proporción de esos terrenos de piedemonte fueron puestos bajo el dominio del capital de manera creciente desde fines del mismo siglo XIX. Las zonas costeras, con suaves planicies que se vuelcan hacia el mar, fueron activadas simultáneamente por sistemas de comunicación

"Hewitt, "Modernización", 1999. 


\section{SECUENCIG}

Mapa 1

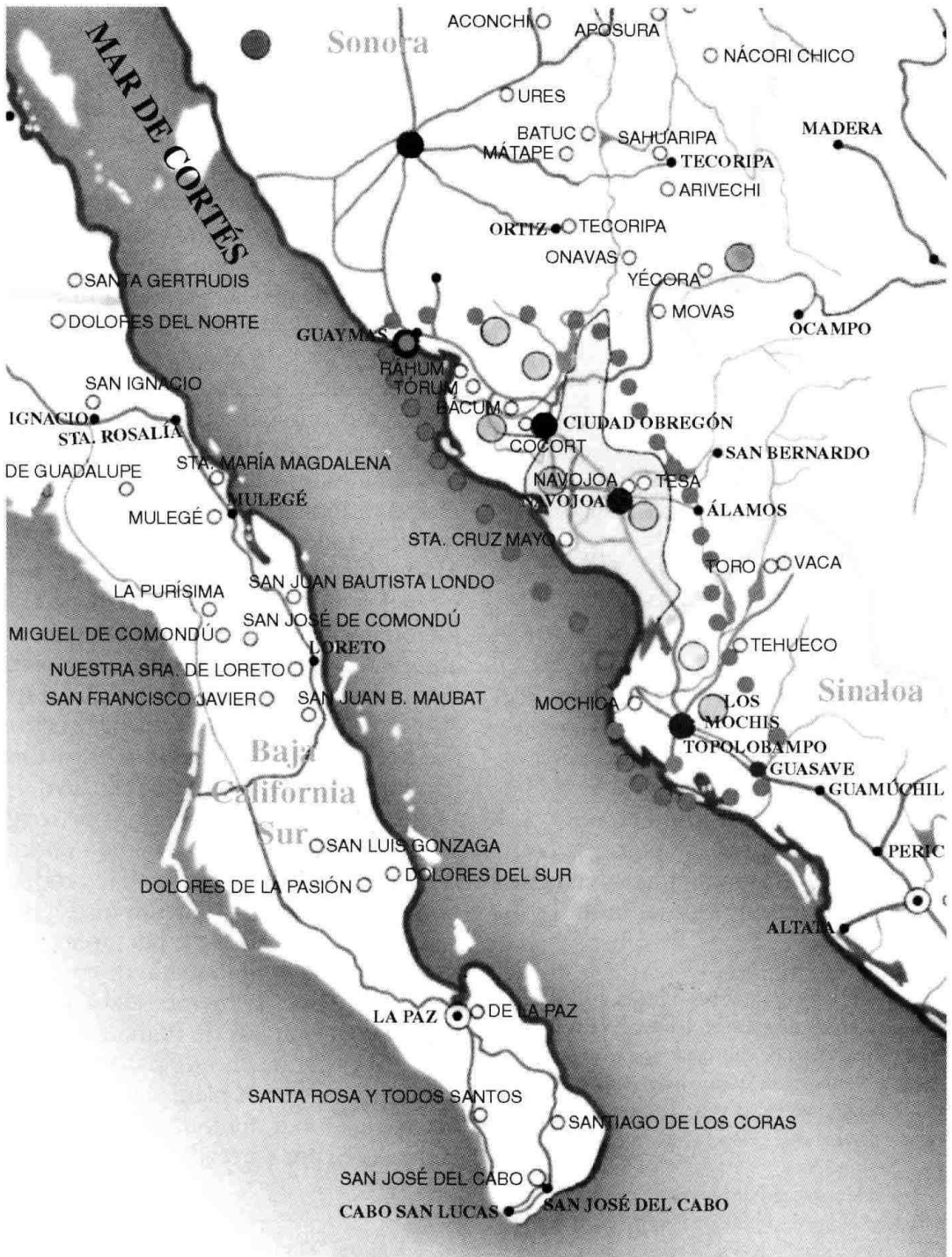


Cuadro 1. Municipios incorporados al estudio

\begin{tabular}{llrr} 
Municipio & \multicolumn{1}{c}{ Cabecera } & Estado & $\begin{array}{r}\text { Superficie actual } \\
\left(\mathrm{km}^{2}\right)\end{array}$ \\
Cajeme & Ciudad Obregón & Sonora & 3312 \\
Guaymas & Guaymas & Sonora & 12208 \\
Empalme & Empalme & Sonora & 709 \\
Bácum & Bácum & Sonora & 1410 \\
San Ignacio Río Muerto & San Ignacio Río Muerto & Sonora & 1144 \\
Benito Juárez & Villa Juárez & Sonora & 399 \\
Etchojoa & Etchojoa & Sonora & 923 \\
Navojoa & Navojoa & Sonora & 2749 \\
Huatabambo & Huatabampo & Sonora & 1170 \\
Ahome & Los Mochis & Sinaloa & 4343 \\
El Fuerte & El Fuerte & Sinaloa & 3843 \\
Guasave & Guasave & Sinaloa & 3464 \\
Superficie a estudiar & & & 35674 \\
Ambos estados & & & 236847 \\
Porcentaje de ambos & & & 15.06 \\
a Las referencias a la superficie de cada municipio suelen variar según la fuente. & \\
Fuentes: intag y páginas web de los municipios. & &
\end{tabular}

Cuadro 2. Población del área seleccionada (2000)

$\begin{array}{llr}\text { Municipio } & \text { Estado } & \text { Población } \\ \text { Cajeme } & \text { Sonora } & 356290 \\ \text { Guaymas } & \text { Sonora } & 130329 \\ \text { Empalme } & \text { Sonora } & 49987 \\ \text { Bácum } & \text { Sonora } & 21322 \\ \text { San Ignacio Río Muerto } & \text { Sonora } & 13692 \\ \text { Benito Juárez } & \text { Sonora } & 21813 \\ \text { Etchojoa } & \text { Sonora } & 56129 \\ \text { Navojoa } & \text { Sonora } & 140650 \\ \text { Huatabampo } & \text { Sonora } & 76296 \\ \text { Ahome } & \text { Sinaloa } & 359146 \\ \text { El Fuerte } & \text { Sinaloa } & 89515 \\ \text { Guasave } & \text { Sinaloa } & 277402 \\ \text { Total población } & & 1592571 \\ \text { Ambos estados } & & 4753113 \\ \text { Porcentaje de ambos } & & 33.50\end{array}$

Fuente: INEGI, Censo de población, 2000. 
que facilitaban el traslado, por tierra ${ }^{9}$ o mar, de los frutos cosechados o transformados en instalaciones industriales que se levantaban en las ciudades que nacían o crecían en el espacio analizado.

Es menester recalcar la utilización sistemática que se hizo de los puertos septentrional y meridional del territorio en estudio: Guaymas, en Sonora, y Topolobambo, en Sinaloa. Ambos puertos sirvieron y ayudaron a integrar, además, un tejido de ciudades próximas que brindaba los beneficios y externalidades ${ }^{10}$ propios de toda trama urbana que asume la forma de red. Este conjunto de ciudades (de tamaño diverso entre lo medio y lo pequeño) se encuentra distribuido en un radio no mayor a los $200 \mathrm{~km}^{11}$ de un hipotético punto central (véase cuadro 3).

Sin dejar de recordar la trayectoria previa de Guaymas, muy ligada al tráfico del Pacífico, Los Mochis emergió como el principal centro urbano del espacio analizado hasta los años treinta del siglo Xx. ${ }^{12}$ Como se puede inferir de los trabajos de María Eugenia Romero, Eduardo Frías,

\footnotetext{
${ }^{9}$ Sobte los ferrocarriles, Gracida, "Llegada", 2001; "Ferrocarril", 2003; "Papel", 2004.

${ }^{10} \mathrm{El}$ concepto externalidad fue muy utilizado por Marshall a fines del XIX, y retomado por los estudiosos italianos de los distritos industriales. Marshall, "Principios", 1957.

${ }^{11}$ La distancia por carretera entre Guaymas y Guasave, en ambos extremos, suma 415 kilómetros.

12 "A partir de la construcción de la Fábrica de Azúcar, la ciudad de Los Mochis se ha desarrollado continuamente y con mucha rapidez y dinamismo [...] En corto tiempo recibió la categoría de alcaldía y luego de sindicarura. Esta categoría perduró hasta 1926, cuando se le concedió la categoría de ciudad. Nueve años después, en 1935, se cambió la cabecera de la municipalidad a Los Mochis, que anteriormente estaba en Ahome." Romero, "Azúcar", 2003, p. 34.
}

Hubert de Grammont y Mario Gill, esa condición se debió a la notable dinámica que se estableció en el norte de Sinaloa, entre otras razones, por: 1) un temprano ciclo de colonización al estilo estadunidense; 2) la instalación de grandes ingenios azucareros; c) la fugaz y ya mítica "época de oro" del tomate, previa a la crisis de 1929.

Pero desde los años treinta, la agilidad productiva y empresarial que envolvería a Ciudad Obregón habría de desplazar paulatinamente tanto a la vecina y más antigua Navojoa como a Guaymas y a Los Mochis como núcleo urbano prominente del territorio en análisis. ${ }^{13}$

\section{HisTORIA MÍNIMA DE LA AGRICULTURA}

Los antecedentes forjados por Carlos Conant y la Sonora and Sinaloa Irrigation, por proyectos colonizadores de origen estadunidense como el que dirigió Albert Owen, las labores llevadas adelante por la Comisión Geográfica y Exploradora de Sonora y la Comisión Científica de Sonora, la acción de la Compañía Constructora Richardson, las múltiples actividades emprendidas por Benjamin Francis Johnston, y el impacto regional de empresas como la Sinaloa Sugar Company y la United Sugar Companies marcaron la dinámica agrícola del área entre 1885 y 1925.

Gustavo Lorenzana resalta, con precisión, que buena parte del desenvolvimiento hidráulico y agrícola inicial de los valles meridionales de Sonora y de la parte norte

${ }^{13}$ Ciudad Obregón aglutina hoy unos 320000 habitantes, lo que supone $90 \%$ de la población de Cajeme, a su vez el municipio más habitado de este territorio biestatal. 
Cuadro 3. Distancias entre ciudades locales (en km)

Desde Guaymas

Obregón: 130

Navojoa: 198

Huatabampo: 236

Los Mochis: 355

Topolobambo: 378

Guasave: 415
Desde Ciudad Obregón

Guaymas: 130

Navojoa: 68

Huatabampo: 106

Los Mochis: 225

Topolobambo: 248

Guasave: 285
Desde Los Mochis

Guasave: 60

Topolobambo: 23

Navojoa: 157

Ciudad Obregón: 225

Guaymas: 355 de Sinaloa fue resultado, justamente, de iniciativas individuales que lograron transformar la llanura semidesértica que bajaba hacia el mar. ${ }^{14}$ Una inferencia similar efectúa Frías Sarmiento para Sinaloa. ${ }^{15}$

En ese contexto se había desarrollado para 1920 una intensa explotación del azúcar; el garbanzo resultaba un excelente artículo de exportación y el tomate apuntaba como una hortaliza con próspero futuro. A la vez, el trigo y el arroz comenzaban a poblar los escenarios locales. La llegada del ferrocarril,${ }^{16}$ que aproximó este espacio al sistema ferroviario de Estados Unidos y unió los terrenos agrícolas con los puertos locales, propulsó la actividad regional, la cual, como derivado multiplicador, incorporó otro elemento fundamental: la agroindustria. ${ }^{17}$

Desde mediados de los años veinte, las ya influyentes políticas del incipiente Estado de la revolución y la de sus representantes y defensores (especialmente en Sonora),

14 Lorenzana, "Obras", 2004, p. 9. "En este esfuerzo, indica Lorenzana, la participación del gobierno federal había sido mínima."

is Frías, "Agricultura".

${ }^{16}$ En 1903 toca El Fuerte y en 1907 arriba a Navojoa.

${ }^{17}$ Manifestada sobre todo en la producción de azúcar, alcohol, harina de trigo y preparación del arroz. tendieron a acentuar esta dinámica. Las tareas empresariales del ex presidente Álvaro Obregón en el sur de Sonora, el control federal que se ejerció sobre la propiedad y gestión de la Compañía Constructora Richardson ${ }^{18}$ y la aparición de bancos y uniones de crédito que apoyaban al sector agrícola de manera específica, ${ }^{19}$ habrían de proporcionar estímulos notorios al desarrollo de la agricultura comercial.

Junto al azúcar, el trigo, el arroz y las hortalizas como el tomate, tomarían la delantera al acercarse la gran depresión, pese a que aún no habían cristalizado las grandes obras que se construirían desde los tiempos de Lázaro Cárdenas. Mientras la reforma agraria modificaba parcialmente los sistemas de tenencia de la tierra, Francis Johnston desaparecía del escenario regional, ${ }^{20}$ se habilitaban presas como La Angostura y la segunda guerra mundial reactivaba la demanda, el valle del Yaqui y Ciudad Obregón emergían con vivacidad en este cambiante escenario biestatal.

${ }^{18}$ En marzo de 1928 el gobierno federal adquiere las acciones de la Compañía Richardson y la entrega al Banco Nacional de Crédito Agrícola, S. A. que se hizo cargo de activos y pasivos de la compañía. En esta operación "fue definitiva la intervención del general Álvaro Obregón".Vargas, Valle, 2004, p. 25.

${ }^{19}$ Historia, 1985; Aguilar, "Banca", 2001.

${ }^{20}$ Romero, "Azúcar", 2003. 
Cambios en el Valle del YaQui

Hacia los inicios del siglo pasado el dato más significativo de la historia contemporánea del río Yaqui, de la planicie que baja de la Sierra Madre y del conjunto llamado valle del Yaqui era tal vez el combate entre miembros y familias de las culturas autóctonas contra los civilizadores de origen mexicano o extranjero, ansiosos por poner suelo y agua bajo el dominio del capital.

La resistencia de los grupos vernáculos soportó diferentes ataques entre 1880 y los años veinte. Finalmente se vieron obligados a ceder parte de las tierras y del agua al Estado y a los agentes económicos que habrían de transformar este rudo desierto en un próspero emporio agrícola.

Se ha narrado en detalle cómo Carlos Conant terminó por traspasar su concesión a la que habría de llamarse Compañía Constructora Richardson S. A., cuyos planes de ocupación y explotación del suelo y sus sistemas de irrigación marcaron el futuro del valle. ${ }^{21}$ Lo que interesa destacar aquí es que, para mediados de los años veinte, la experiencia y acciones de la Compañía Richardson habían resultado lo suficientemente significativas como para que su retirada no frustrara los proyectos de colonización, ampliación de la frontera agrícola y puesta en marcha de grandes proyectos de irrigación. ${ }^{22}$

${ }^{21}$ Entre otros, Fujigaki, Modernización, 2001; Lorenzana, "Compañías", 2004; Historia, 1985, t. v; Vargas, Valle, 2004; Depredadores, 2003.

${ }^{22}$ Fenómeno verificable con amplitud en las escrituras de la época. Ver libros de notarios del Archivo General del Estado de Sonora (en adelante AGES). Planes y acciones, por otro lado, comparables a los realizados en otros lugares de América Latina, en especial en la Argentina del cereal desde 1870.
Ya en 1917, según describe Fujigaki Cruz, la constructora había abierto 550 kilómetros de canales y una presa de derivación provisional. El área cultivable "llegaba a 30000 hectáreas" y cuando los canales terciarios sè terminaran aumentaría a 44000 . También había construido 630 kilómetros de caminos, 150 puentes y 80 kilómetros de líneas telefónicas. ${ }^{23} \mathrm{Y}$ en el momento en que el ingeniero Alberto Vargas Martínez arribó a Esperanza procedente de Hidalgo, en octubre de 1923, encontró lo siguiente:

Ahí estaba ya la obra realizada por el coronel Carlos Conant y la Sonora-Sinaloa Irrigation Co., en diez años de duras tareas, impulsando la primera gran etapa del desarrollo del Sistema de Riego del valle del Yaqui. Y seguía con mucho ímpetu la segunda etapa por la Compañía Constructora Richardson $S$. A., después de un receso de ocho años (1900-1908), por suspensión de contrato, y de otros trece años (1909-1922) de nuevas actividades pero con innumerables interrupciones forzosas. ${ }^{24}$

Cuando Vargas Martínez llegó a trabajar al Departamento de Ingenieros, "las actividades de la Compañía Richardson estaban en todo su apogeo y Esperanza vivía una pequeña bonanza". Cocorit era entonces el centro del valle, con más antigüedad y habitantes que la cercana Esperanza, cabecera municipal. Cocorit contaba con oficina de telégrafos, correo,

${ }^{23}$ Fujigaki, Modernización, 2001, p. 68.

${ }^{24}$ Vargas, Valle, 2004, p. 16. Narra luego que trabajó "bajo la administración norteamericana cuatro años y medio" y siguió con la administración mexicana de la compañía "catorce años más, llegando a ocupar el puesto de jefe del Departamento de Ingeniería". 
juzgados y recaudación de rentas. "Allí vivían los ricos y la gente bien, entre los que sobresalían terratenientes y agricultores", describe Vargas.

En aquellos años los principales cultivos eran "el arroz en el verano, que se sembraba en $60 \%$ de la superficie de riego; (y) trigo en el invierno, con 30\%". El arroz ocupaba la mayor superficie porque se aprovechaban las "avenidas de aguas broncas del río en la temporada de lluvias, de julio a septiembre". ${ }^{25}$ En 1923 las hectáreas bajo riego superaban las 15000 , distribuidas entre terrenos yaquis y las que trabajaban inmigrantes extranjeros y colonos mexicanos. ${ }^{26}$

La dilatación de la frontera interior impuesta por el capital, la expansión de las hectáreas irrigadas y cultivadas, no cesaría. Como bien han recordado diversos autores, mucho tuvieron que ver en este proceso las políticas agrícolas, crediticias y de irrigación que tanto el Estado federal como el de Sonora desarrollaron desde mediados de los veinte. En el mismo valle del Yaqui dos factores se sumaron desde 1925: la llegada y actividad del mismísimo Álvaro Obregón, por un lado; y el control del Estado federal sobre los derechos y concesiones de la Compañía Constructora Richardson, por el otro.

Obregón se había instalado de hecho en el valle del Mayo desde antes de entregar la presidencia. Allí no sólo se dedicaba a sembrar garbanzo, sino que además propuso y llevó adelante la construcción de un ferrocarril de Navojoa al puerto de Yá-

${ }^{25}$ Vargas, Valle, 2004, pp. 85 y 95-97.

${ }^{26}$ Lorenzana, "Avance", 2005, p. 3, indica que para 1917 el área nueva de irrigación se aproximaba a las 30000 hectáreas. varos. ${ }^{27}$ Cuando se registró la quiebra de la Richardson, consecuencia en fuerte medida de la arrasadora inundación de 1923, el ya ex presidente influyó para que el gobierno federal adquiriera en 1926 la totalidad de las acciones de la sociedad.

El control de esta compañía lo ejerció desde entonces el recién fundado Banco Nacional de Crédito Agrícola y Ganadero, institución que "se dedicó de inmediato a prolongar canales a fin de abrir nuevas áreas al cultivo, aumentar la capacidad de éstos, reparar puentes y compuertas... y la producción tuvo un aumento rápido". ${ }^{28}$

Mientras, Álvaro Obregón proseguía con intensidad su devenir empresarial, ahora prolongándolo al valle del Yaqui. Según el ingeniero Vargas, quien lo conoció personalmente, al terminar su mandato, en diciembre de 1924, el general se afincó en Navojoa y desde allí promovió la apertura de 2000 hectáreas de tierras en el Yaqui "para dedicarse a la agricultura". Parte de esas tierras las compró a la Compañía Agrícola Náinari, L. C., con las que constituyó la hacienda Náinari, en la que se apresuró a desmontar, preparar la tierra y sembrar. Construyó su casa habitación, vivienda para los trabajadores y "almacenes, cobertizos para la maquinaria agrícola así como talleres".

En estación Cajeme, en terrenos del Sudpacífico, Obregón levantó un edificio para sus oficinas. También construyó una planta de fuerza para dar servicio de elec-

${ }^{27}$ Gracida, "Ferrocarril", 2003.

${ }^{28}$ Dabdoud, Historia, 1995, p. 327. Según este autor, la noticia de la compra de la Richardson "causó un júbilo muy grande en Sonora, particularmente entre los agricultores mexicanos del nuevo valle". Sobre las políticas oficiales y proyectos bancarios de estos años, véase Oñate, Banqueros, 1991. 


\section{SECUENCIA}

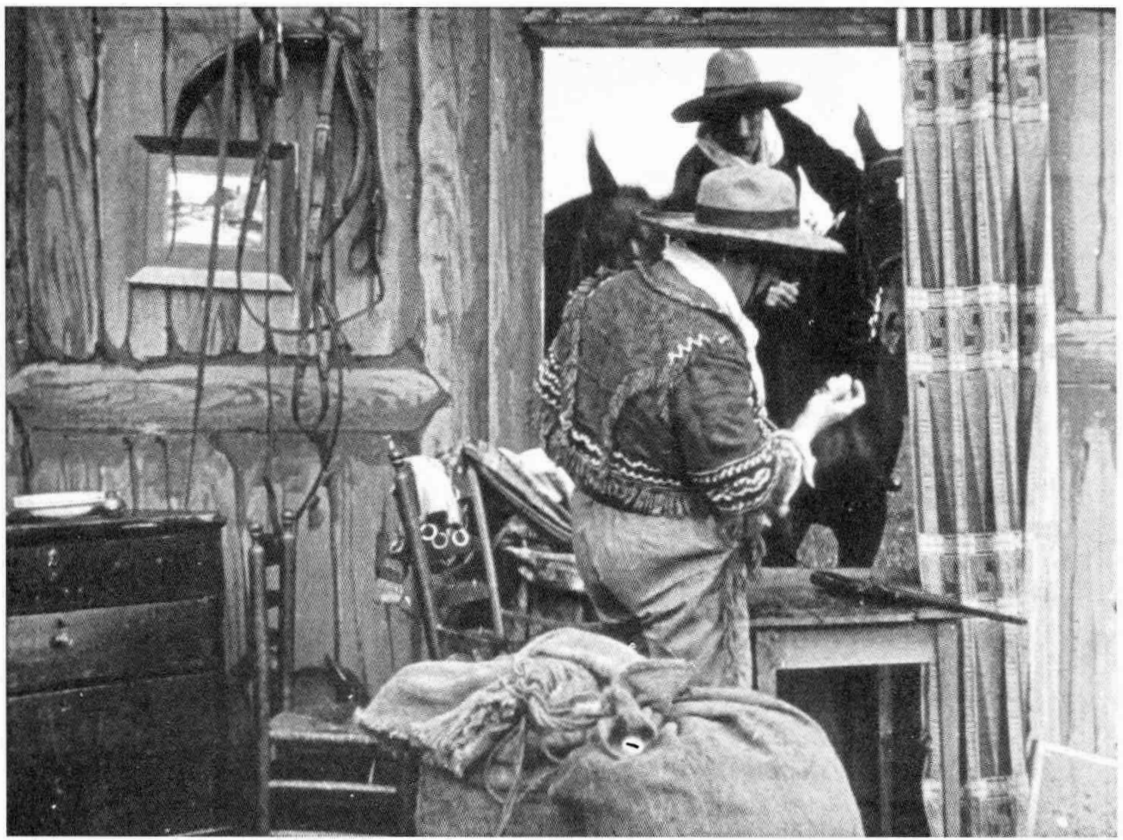


tricidad a la planta de bombeo y de alumbrado a su hacienda. La planta se estableció en-terrenos de lo que sería Ciudad Cajeme, "pues a iniciativa del general ya se había trazado el fundo de esa población". Y para ampliar sus negocios en el lugar, adquirió la mayoría de las acciones de la Compañía Molinera del Río Yaqui (propiedad de agricultores estadunidenses), levantó almacenes, una empacadora de comestibles, una pequeña despepitadora de algodón y un dispensario para los trabajadores. ${ }^{29}$

Dabdoud resume por su lado que dentro de esta mecánica expansiva las hectáreas cultivadas en el valle habían saltado de 15000 en 1923 a 37000 antes de terminar la década de los veinte. Para el ciclo 1937-1938, remata, se habían puesto en cultivo más de 52000 hectáreas. $^{30}$

\section{LAS GRANDES PRESAS}

Hewitt de Alcántara, Hubert de Grammont, Lorenzana y Frías Sarmiento se cuentan entre los estudiosos que han resaltado el papel de las grandes obras de irrigación en el desenvolvimiento de un agricultura especializada en el noroeste de México.

Según cifras sistematizadas por Hewitt (véase cuadro 4), Sonora y Sinaloa concentraron $30 \%$ de la inversión total entre 1940 y 1970 , época que incluyó la habilitación de las tres presas que regularían agua y energía eléctrica en el valle del Yaqui: La Angostura (Lázaro Cárdenas), Oviachic (Álvaro Obregón) y El Novillo (Plutarco Elías Calles).

\footnotetext{
${ }^{29}$ Vargas, Valle, 2004, pp. 107-108.

${ }^{30}$ Dabdoud, Historia, 1995, p. 331.
}

La Angostura se levantó en la parte septentrional de la cuenca del Yaqui, sobre el río Bavispe, 130 kilometros arriba de la confluencia de ambos ríos. Impulsada por el gobierno de Cárdenas, se terminó de construir en 1940 aunque las primeras extracciones regulares de agua se registraron en 1942. Gracias a esta presa, la superficie potencial de riego en el bajo Yaqui pasó de 42000 hectáreas a 120000 hectáreas. ${ }^{31}$

Aunque las cifras no siempre coinciden (o se brindan bajo parámetros diferentes), en general convienen en el sistemático incremento del área agrícola. Un detallado informe de 1946-1947 puntualizaba de qué manera, a partir de 1911-1912 y cada cinco años, habían aumentado las hectáreas cultivadas (véanse cuadro 5 y gráfica 1).

Oviachic fue montada en la boquilla que forman los cerros de Oviachic y de la Cantera a sólo 40 kilómetros de Ciudad Obregón y dentro del mismo municipio de Cajeme (véase mapa 2). Se construyó durante el gobierno de Miguel Alemán, fue concluida en 1952 y entró en operaciones en 1953. Permitió incrementar la capacidad potencial de riego en el valle ciel Yaqui a 230000 hectáreas. ${ }^{32}$

Ya en el informe de Ortega Leite se anticipaba que Oviachic sería "una de las

${ }^{31}$ Vargas, Valle, 2004, pp. 145 y ss. El informe Ortega Leite señalaba en 1946-1947 que debía llegarse a 121000 hectáreas "bajo las condiciones actuales de aprovechamiento de los escurrimientos del río Yaqui". Más adelante aclaraba que esto era en "la margen izquierda". Aclaraba asimismo que "apenas se ha sobrepasado $50 \%$ del área total que se podrá regar al aprovechar al máximo los recursos hidráulicos del río Yaqui". Ortega, "Datos", s. a., pp. 25 y 28.

${ }_{32}$ Ortega, "Datos", s. a., pp. 163 y ss.; Dabdoud, Historia, 1995, p. 366, señalaba en 1964 que "el área de cultivo" llegaba a unas 230000 hectáreas. 


\section{SECUENCIG}

Mapa 2

B. $C$

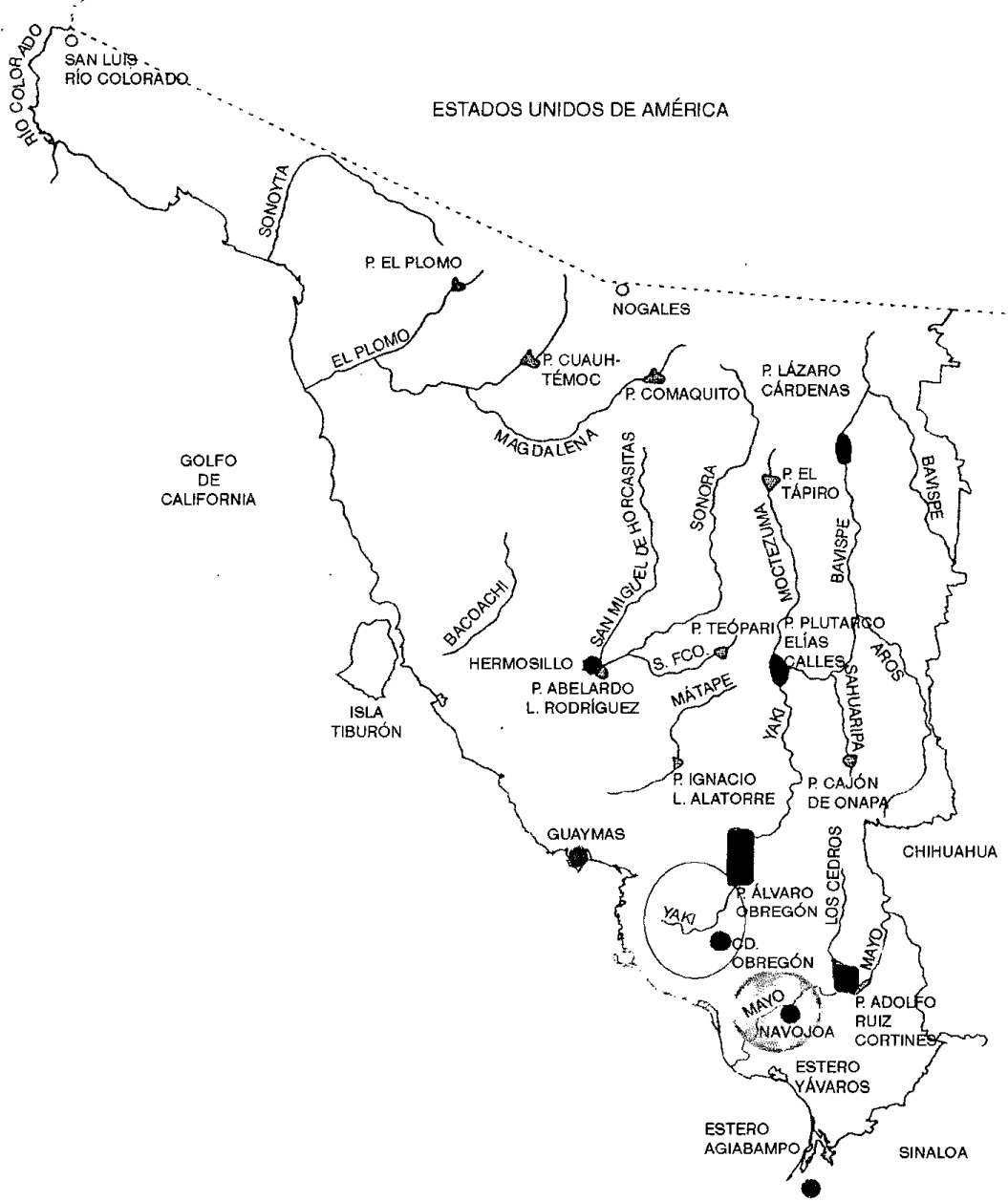


Cuadro 4. Inversiones en proyectos de irrigación (1941-1970) (en miles de pesos de 1950)

Estado
Sinaloa
Tamaulipas
Sonora
Península B. California
Chihuahua
Total México
Sinaloa/Sonora

Fuente: Hewitt, 1999, p. 29.

$\begin{array}{cc}\text { Inversiones } & \text { Porcentaje } \\ 1302736 & 22.26 \\ 606990 & 10.36 \\ 452664 & 7.73 \\ 403743 & 6.90 \\ 341795 & 5.84 \\ 5853550 & 100.00 \\ 1755400 & 29.99\end{array}$

bas obras que facilitará la industrialización de los productos agrícolas y ganaderos". 34 Finalmente, El Novillo ${ }^{35}$ se levantó en el sitio del mismo nombre, que coincide con la confluencia de los ríos Moctezuma y Aros. Se construyó durante el mandato de Adolfo López Mateos, y comenzó a operar en 1965 . En realidad, su objetivo fundamental fue la generación de energía, ${ }^{36}$ insumo estratégico para el desarrollo agroindustrial urbano.

De esta manera, el valle o sistema del Yaqui terminó de configurarse como el Distrito de Riego 041 que, según se sintetiza en el cuadro 6, sumaba en 1959 más de $59 \%$ de la superficie irrigada por gravedad en Sonora. Si al Yaqui se le agregaba el sistema contiguo del Mayo, la proporción rozaba el $80 \%$ dentro de tan extenso estado del noroeste (véase gráfica 2).

"por las características propias de la obra como por las de la zona que beneficiará con el riego". Al combinar su manejo con $\mathrm{La}$ Angostura ${ }^{33}$ no sólo se lograría un mejor aprovechamiento agrícola; también se podría "generar energía hidroeléctrica en am-

33346 kilốmetros aguas arriba. Ortega, "Datos", s. a., p. 29.

${ }^{34}$ lbid.

${ }^{35}$ Vargas, Valle, 2004, pp. 229 y ss.

${ }^{36} \mathrm{La}$ capacidad global de riego no ha rebasado las 325000 hectáreas. "El Novillo [...] no es de almacenamiento para fines agrícolas, sino para la generación de 90000 kwts más de electricidad." Dabdoud, Historia, 1995, p. 367. 


\section{SECUENCIA}

Gráfica 1. Área bajo cultivo (1911-1946)

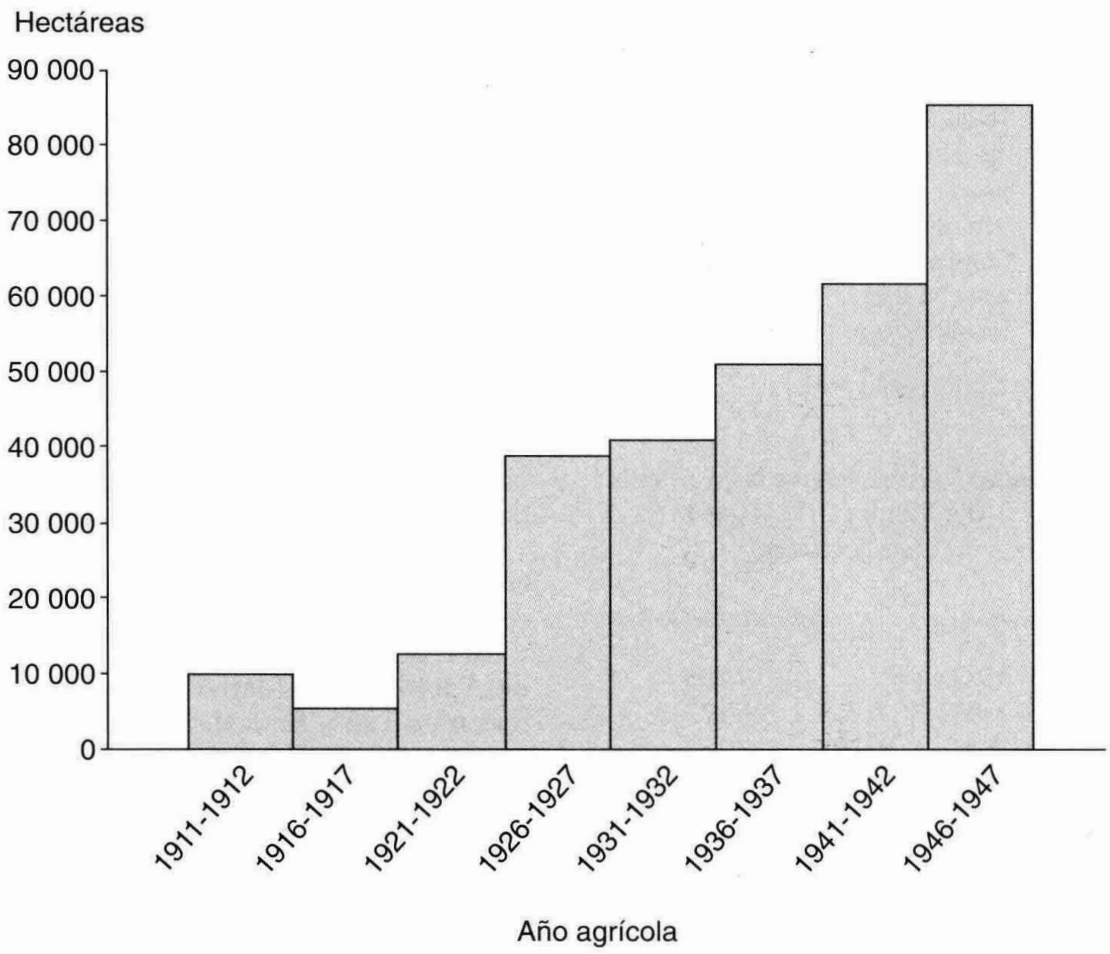

Fuentes: AGES, Libros de notarios (1925-1960) y Archivo General de Notarías del Estado de Sonora (en adelante AGNES).

Cuadro 6. Superficie irrigada por gravedad (ambos valles, 1959)

Sistema Yaqui

Sistema Mayo

Ambos valles

Sonora
Hectáreas

Yaqui/Sonora

$59.3 \%$

80000

310000

388000
Ambos/Sonora

$79.9 \%$

Fuente: Adaptado de Historia, 1985, t. v, p. 164. 


\section{SECUENCIA}

Gráfica 2. Riego por gravedad (1959)

Miles de hectáreas

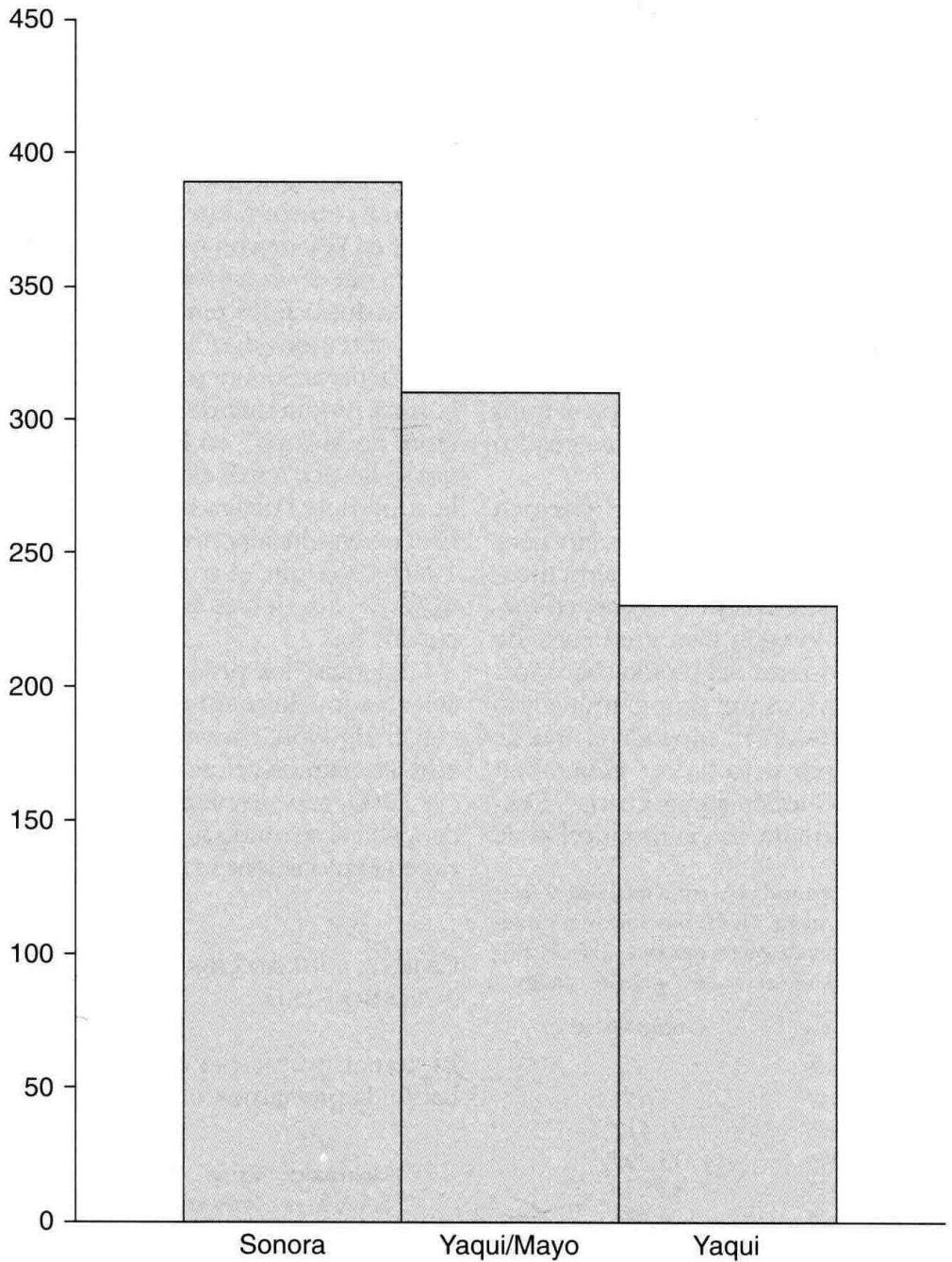

Fuentes: AGES, Libros de notarios (1925-1960) y AGNES. 


\section{TIERRA Y CULTIVOS}

La ocupación agrícola bajo dominio del capital, que inició con cierta lentitud, se expandió de manera visible en el valle del Yaqui a partir de la mitad de los años veinte. Como indicaba el ya citado informe Ortega, se pasó de unas 15000 hectáreas bajo cultivo y replantadas en 19231924 a unas 47000 diez años más tarde, para alcanzar en 1945-1946 más de 86000 . Dentro de estas cifras globales, habrían de sobresalir nuevos cultivos. El arroz y el trigo, que comenzarían a definir el carácter agroindustrial de Ciudad Obregón, tomaron la delantera ya a principios de los mismos años veinte (véanse cuadro 7 y gráfica 3). ${ }^{37}$

Y de acuerdo con María del Carmen Hernández, para la década de los cincuenta la economía sustentada en la agricultura "se había terminado de afianzar" en torno a Ciudad Obregón y en gran parte de las planicies costeras del estado (Navojoa, Etchojoa, Guaymas y el propio municipio de Cajeme incluidos). Sumando el área de Hermosillo, por otro lado, "generaban 90\% de la producción agropecuaria". Desde los años cuarenta, así, la producción de

${ }^{37} \mathrm{La}$ linaza, destinada casi en su totalidad al mercado de Estados Unidos, viviría una auténtica explosión durante la segunda guerra mundial. El área cultivada, en hectáreas, presentaba el siguiente cuadro:

$\begin{array}{lc}\text { Año agricola } & \text { Cultivo linaza } \\ 1940-1941 & - \\ 1941-1942 & 1455 \\ 1942-1943 & 21512 \\ 1943-1944 & 13299 \\ 1944-1945 & 12243 \\ 1945-1946 & 4874 \\ 1946-1947 & 11251\end{array}$

Fuente: Orrega, "Datos", s. a., cuadro 10. trigo en el sur de Sonora sobresalía "en el contexto nacional por sus índices de rendimiento sensiblemente superiores a los de la media nacional". Dicha entidad federativa se distinguía asimismo "por ser la única en la que se realizaba una explotación mecanizada". ${ }^{38}$

Esta posición quedó fortalecida "cuando los valles agrícolas", con el del Yaqui en primer término, fueron elegidos para poner en práctica un nuevo paquete tecnológico - la revolución verde-, que "prácticamente duplicó los rendimientos por hectárea obtenidos diez años antes". ${ }^{39}$

Mientras Sonora se consolidaba como la zona productora de trigo "más importante de México", en los terrenos del Yaqui se llevaba a más de 100000 hectáreas la superficie cultivada con este cereal. ${ }^{40}$ Esta extensión suponía en el ciclo agrícola 1960-1961 que el trigo ocupaba más de $42 \%$ de las tierras bajo cultivo (véase cuadro 8).

Además, los productores resultaban acicateados de manera complementaria con el algodón, convertido descle tiempo atrás en materia prima de exportación: hacia 1960, tras desplazar al arroz, la fibra ocupaba el segundo lugar en tierras puestas en explotación: más de 21 por ciento.

\section{Cajeme, Ciudad Obregón, AGROINDUSTRIA}

El actual municipio de Cajeme ${ }^{41}$-área habitada previamente por los pueblos ya-

\footnotetext{
${ }^{38}$ Hernández, "Crisis", 2001, p. 157.

${ }^{39}$ Sobre la revolución verde en el sur de Sonora, véase Hewitt, Modernización, 1999.

${ }^{40}$ Dabdoud, Historia, 1995, p. 379.

${ }^{41}$ Véanse cuadros 1 y 2.
} 


\section{SECUENCIA}

Cuadro 7. Principales cultivos en el valle del Yaqui (1911-1946)

(en hectáreas)

$\begin{array}{lrrrrrrrr} & 1911- & 1916- & 1921- & 1926- & 1931- & 1936- & 1941- & 1945- \\ \text { Año agrícold } & 1912 & 1917 & 1922 & 1927 & 1932 & 1937 & 1942 & 1946 \\ \text { Total bajo cultivo } & 9593 & 6177 & 14081 & 41590 & 43681 & 54729 & 65989 & 86614 \\ \text { Cultivo trigo } & 1064 & 390 & 5428 & 14950 & 12263 & 32973 & 30226 & 35274 \\ \text { Cultivo arroz } & 207 & 592 & 2861 & 17343 & 14762 & 13887 & 25880 & 28593 \\ \text { Cultivo garbanzo } & 278 & 2227 & 692 & 1107 & 143 & - & 654 & - \\ \text { Cultivo linaza } & - & - & - & - & 2508 & - & 1455 & 4874\end{array}$

Fuentes: Ortega, "Datos", s. a., cuadros 3 y 10.

Gráfica 3. Trigo, arroz y garbanzo en el Yaqui (1913-1946)

Hectáreas en cultivo

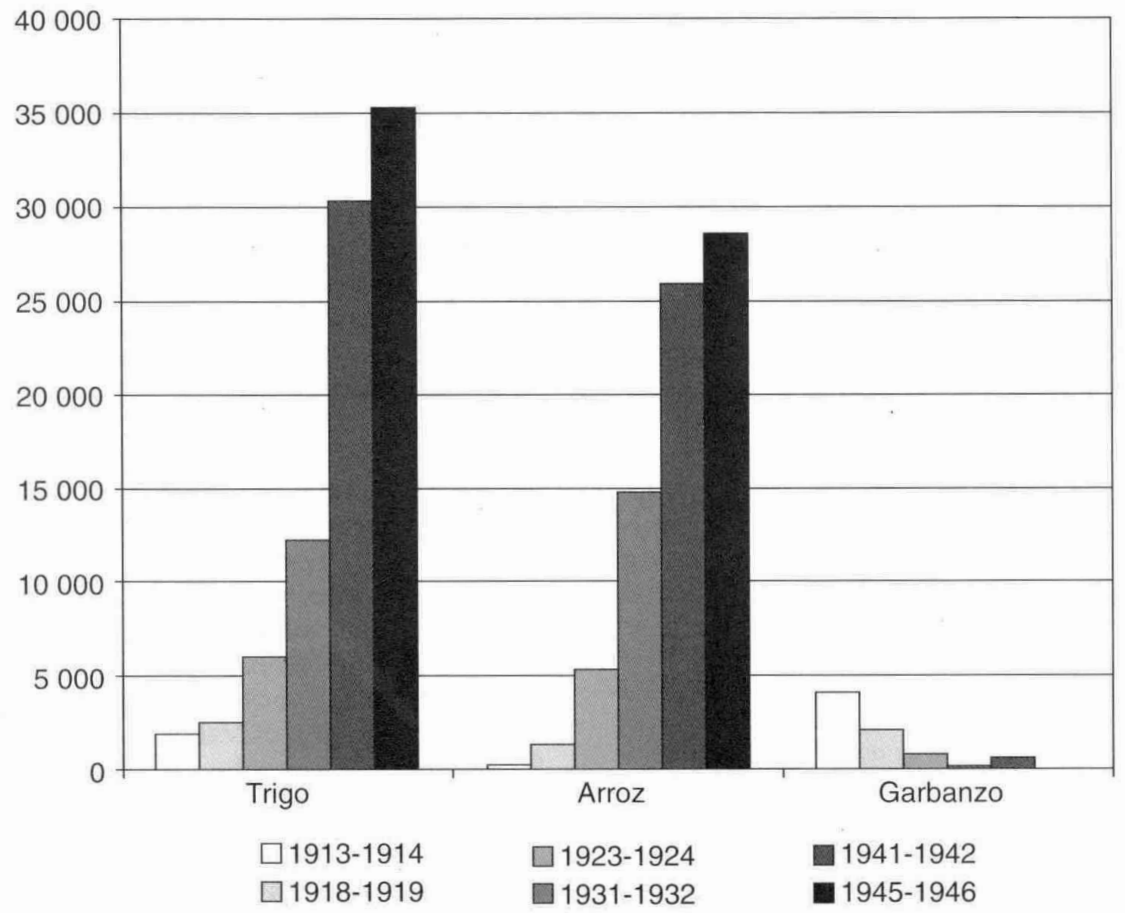

Fuentes: AGES, Libros de notarios (1925-1960) y AGNES. 
Cuadro 8. Hectáreas en explotación en Valle del Yaqui (1960-1961)

$\begin{array}{rrrrrrr}\text { Trigo } & \text { Algodón } & \text { Maíz } & \text { Ajonjolí } & \text { Arroz } & \text { Cebada } & \text { Total } \\ & & & & & & \\ 110685 & 56041 & 23016 & 22047 & 14519 & 12447 & 258916 \\ (42.75) & (21.65) & (8.89) & (8.51) & (5.61) & (4.81) & (100)\end{array}$

Las cifras entre paréntesis corresponden al porcentaje.

Fuente: Dabdoud, Historia, 1964, p. 379.

quis- estuvo adscrito al distrito de Guaymas durante la segunda mitad del XIX. En 1912 el Ferrocarril Sud Pacífico estableció una estación de bandera llamada Cajeme, al sur del pueblo de Cocorit. ${ }^{42}$ Hasta noviembre de 1927, cuando fue ascendido a la categoría de municipalidad, el territorio de Cajeme integraba el municipio de Cocorit. A su vez, Cocorit quedaría subordinada a Cajeme en diciembre de 1930.

La cabecera (Ciudad Cajeme, que antes de noviembre de 1927 tenía rango de comisaría) pasó a llamarse Ciudad Obregón el 28 de julio de 1928, poco después del asesinato del ex presidente. ${ }^{43}$ Según los registros notariales revisados y de versiones como la del cronista Dabdoud, Ciudad Obregón y su entorno ingresaron a un evidente desarrollo agrícola y agroindustrial entre 1930 y 1945 , desenvolvimiento que de todos modos habría quedado recortado por "los transportes deficientes y costosos",

${ }^{42}$ Hasta 1925 los centros de operaciones del valle eran Esperanza y Cocorit, situados a nueve y once kilómetros al norte de donde se enclavaría Ciudad Obregón.

${ }^{43}$ Ocurrida el 17 de julio de 1928 . Autores locales señalan que Obregón "influyó en la mexicanización del valle, impulsó la agricultura e industria y radicó ahí hasta su muerte". Dabdoud, Historia, 1995, p. XXIII. un mercado regional "raquítico" y las "desorbitadas" exigencias de los obreros. ${ }^{44}$

El Informe Ortega indicaba a mediados de los años cuarenta que el arroz se situaba en un lugar preponderante en el valle del Yaqui: se lo consideraba "el cultivo típico" de la zona, el que había "permitido que la agricultura [...] alcance un grado muy avanzado de maquinización, pues en la casi totalidad de sus labores intervienen motores de combustión interna". Pero tras suyo, inmediatamente, figuraba el trigo, al cual Ortega evaluaba como "el cultivo más maquinizado en la región". Con excepción del riego, "todas las demás labores se ejecutan con el uso de maquinaria accionada por motores de combustión interna". ${ }^{45}$

Para 1955 el municipio de Cajeme generaba más de $35 \%$ del producto agrícola del estado de Sonora y poco menos de $34 \%$ de su producto industrial. Si se sumaba Navojoa, en el valle del Mayo, ambas proporciones subían a 61.3 y a $47.2 \%$ respectivamente (veánse cuadro 9 y gráficas 4 y 5), lo que ratifica la importancia económica que estos valles del sur de Sonora habían alcanzado a mediados del siglo $\mathrm{xx}$.

\footnotetext{
${ }^{44}$ Ihid., p. 381.

${ }^{45}$ Ortega, "Datos", s. a., pp. 52-61.
} 


\section{SECUENCIA}

Cuadro 9. Producción agroindustrial de Cajeme y Navojoa (1955) (en miles de pesos)

Obregón/Cajeme Sonora Sonora (\%) Cajeme/Navojoa Sonora (\%)

$\begin{array}{lrrrrr}\text { Agricultura } & 377468 & 1060305 & 35.6 & 649966 & 61.3 \\ \text { Transformación } & 743499 & 2197813 & 33.8 & 1038332 & 47.2 \\ \text { Ambos rubros } & 1120967 & 3256118 & 34.4 & 1688298 & 51.8\end{array}$

Fuente: Adaptado de Historia, 1985, p. 158.

Gráfica 4. Producción agrícola comparada (1955)

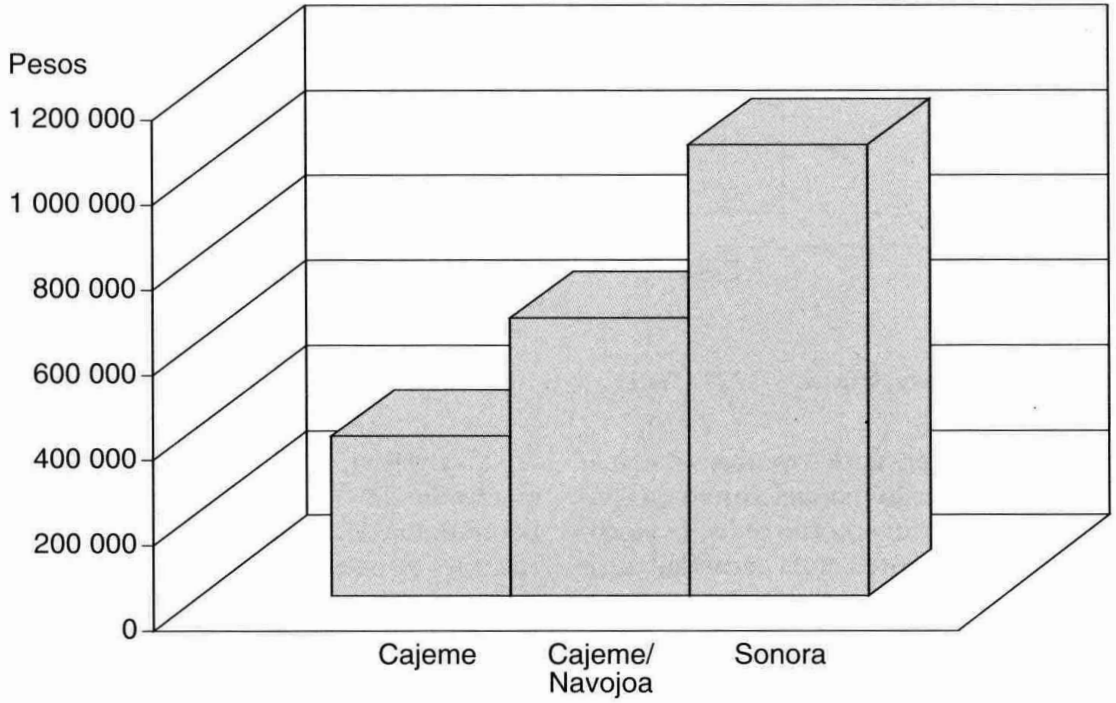

Fuentes: AGES, Libros de notarios (1925-1960) y AGNES. 
Gráfica 5. Industria de transformación (1955)

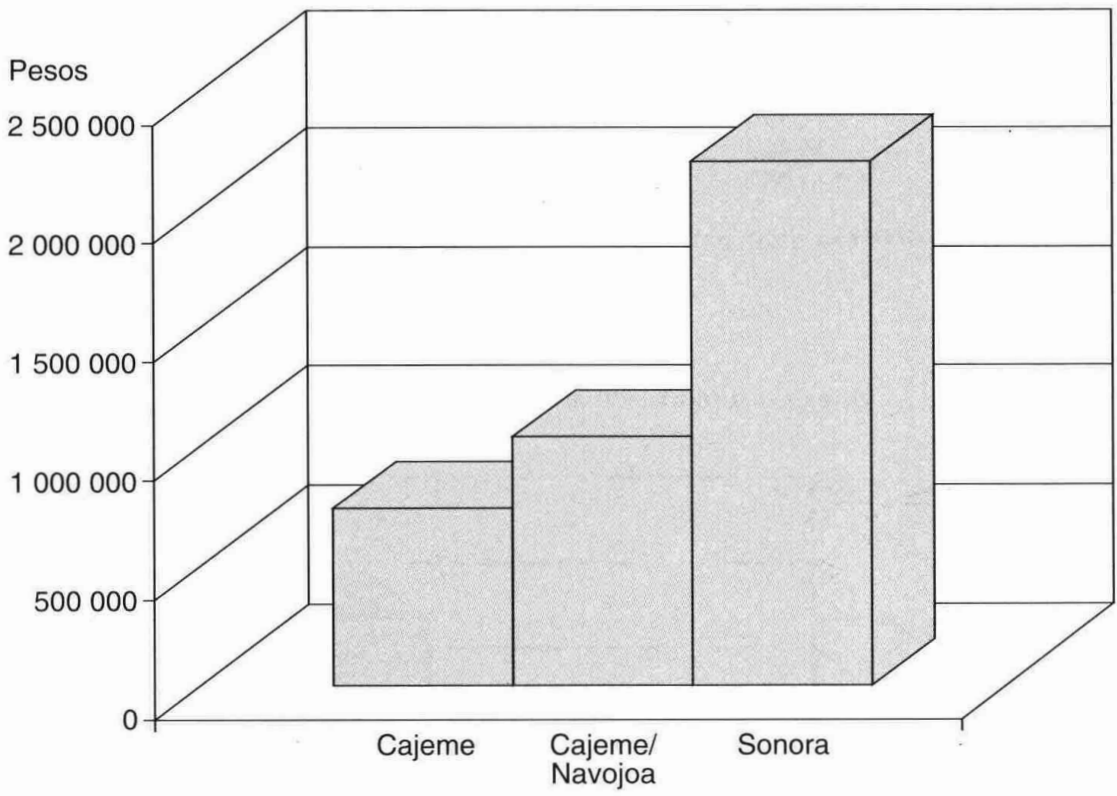

Fuentes: AGES, Libros de notarios (1925-1960) y AGNES.

Como se habría de resumir años más tarde, el desarrollo manufacturero de Ciudad Obregón y su entorno se había vinculado estrechamente con la actividad agrícola. Se conformó principalmente con establecimientos que transformaban los productos agropecuarios, o bien con empresas productoras de insumos: molinos harineros, elaboradoras de galleta, aceiteras, algodoneras, despepitadoras, plantas productoras de fertilizantes, plaguicidas y semillas mejoradas y hasta fábricas de implementos agrícolas. ${ }^{46}$

${ }^{46}$ Municipios, s. a., p. 101.
Y en 1964, según Dabdoud, existían en el valle del Yaqui, entre otros, 18 despepitadoras de algodón, tres molinos extractores de aceites, cinco molinos harineros, cinco molinos arroceros, dos plantas pasteurizadoras de leche, una planta secadora de arroz, dos fábricas de productos alimenticios, una empacadora de carnes frías, tres mezcladoras de insecticidas agrícolas, 28 granjas avícolas. ${ }^{47}$

$\mathrm{Al}$ finalizar la segunda guerra mundial operaban también en Ciudad Obregón dos uniones de crédito (Unión de Crédi-

${ }^{47}$ Dabdoud, Historia, 1995, pp. 382-383. 
to Agrícola del Yaqui y Unión de Crédito Agrícola de Cajeme), además de contarse con agencias y oficinas del Banco Nacional de Crédito Agrícola, del Banco Agrícola Sonorense, del Banco Nacional de México, del Banco del Pacífico, del Banco de Crédito Industrial y Agrícola de Occidente y del Banco Nacional de Crédito Ejidal. ${ }^{48}$

\section{FERTILIDAD EMPRESARIAL (1925-1955)}

Fue Alfred Marshall quien desarrolló en sus estudios de fines del siglo XIX imágenes que permitían visualizar el conjunto empresarial delineado sobre un tejido productivo regional o urbano como un bosque: en su interior nacían, crecían y morían árboles que pugnaba por salir adelante.

El planteamiento del economista inglés - cuyos trabajos y razonamientos sobre las aglomeraciones industriales han sido recuperados en tiempos recientes, en particular por estudiosos italianos- ${ }^{49}$ aludía a los tiempos vitales que podían transitar los negocios dirigidos de manera personal. ¿Qué podía suceder tras el nacimiento de una empresa?

Aquí -planteaba Marshall- podemos aprender una lección de los jóvenes árboles del bosque cuando se esfuerzan por desarrollarse bajo la sombra perjudicial de sus rivales más viejos. Muchos sucumben en su empeño, y

4h Ortega, "Datos", s. a., pp. 65-69.

49 En especial por sus aseveraciones en torno a las economías externas y de escala que se suscitan en un distrito industrial, las demandas y aprovisionamientos mutuos que generan las redes de pequeñas empresas, y el consiguiente impacto sobre crecimiento económico. Véanse Becattini, Marsball, 1981; "Anomalías", 2002, entre otros. sólo unos pocos sobreviven; esos pocos se hacen más fuertes cada año, obtienen mayor cantidad de luz y de aire a cada aumento de su altura, y por último destacan sobre sus vecinos.

Ello, empero, no les aseguraba inmortalidad: "no ocurre asî" porque "más tarcle o más temprano la edad se manifiesta en todo", y el rigor de los años los afectará. Un proceso comparable "sucedía con los negocios" y con sus principales impulsores, a los cuales el tiempo puede debilitar $y$ hacer desaparecer. ${ }^{50}$

Recordar a Marshall y hablar de nacimiento, desarrollo y desaparición de empresas nos acerca a la demografía empresarial, una disciplina que en tiempos recientes se ha desenvuelto sobre todo en Europa del sur a partir de investigaciones que han desarrollado franceses, italianos y españoles.

La demografía empresarial procura reproducir para el mundo de las empresas lo que la demografía como disciplina efectúa respecto a los seres humanos y a las sociedades, más allá de sus componentes étnicos o espacios geográficos donde actúen. Es decir, estudia, entre otras cosas y con los datos a su alcance, los ciclos de nacimiento, crecimiento, desarrollo, declinación y mortandad individual y/o colectiva de las empresas, cualesquiera que hayan sido o fueren la actividad, sector, tamaño o forma de organización que presenten. En otras palabras, procura escudriñar el

50 "Aunque los mayores reciban más luz y mís aire que sus rivales, todos van perdiendo gradualmente su vitalidad, y uno tras otro van dejando el lugar a [aquellos que] con menos fuerza material, tienen a su favor el vigor de la juventud." Marshall, Principios, 1957, p. 263. 


\section{SECUENCIA}

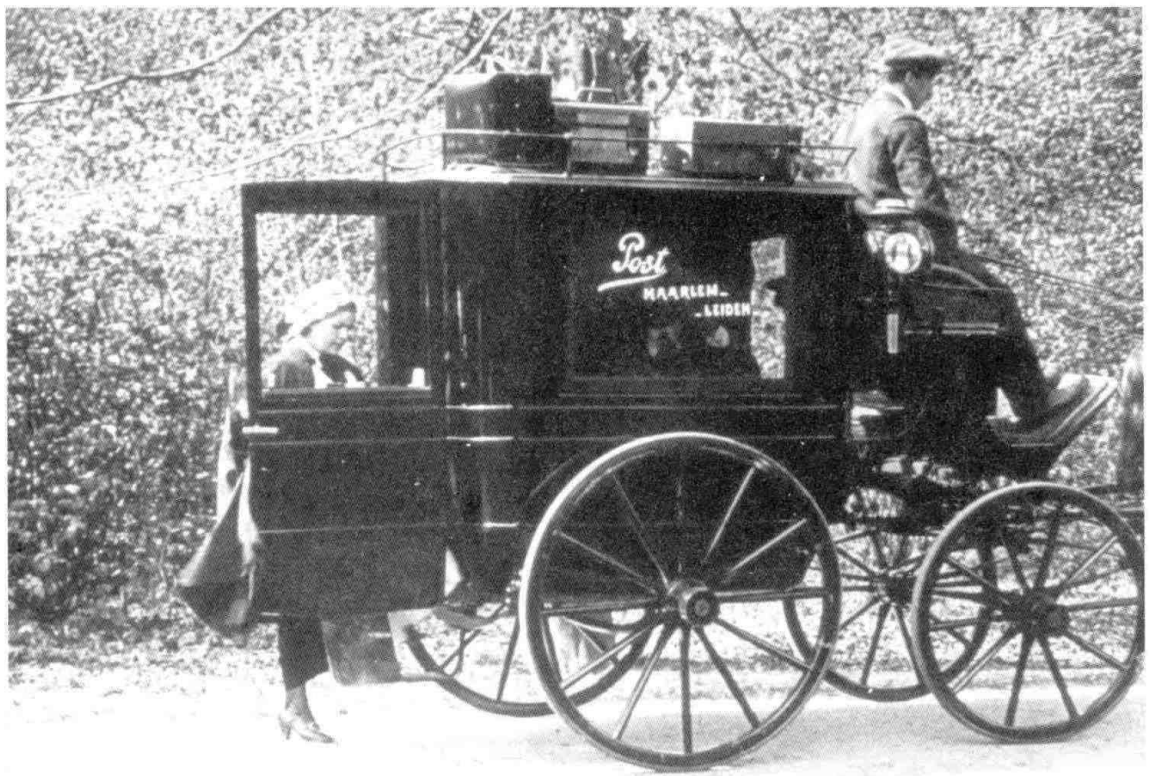


mundo de la empresa en una o más de sus fases vitales.

Este marco conceptual y su respectiva instrumentación han sido aplicados para núcleos urbanos, territorios o regiones que llegaron a llamar la atención por su fertilidad o capacidad para crear y procrear empresas, y que -además- presentan una historia secular en el universo de la actividad empresarial..$^{51}$

De la radiografía factible de efectuar gracias a la demografía empresarial se han obtenido diferentes conclusiones. Una de ellas alude a la capacidad de engendrar empresas y empresarios que pudo existit (o existe) en un espacio regional determinado, en una aglomeración urbana o en un entramado específico de ciudades. Aunque también sería posible estimular más interrogantes o plantear otros problemas, ${ }^{52}$ limitaremos los objetivos de este breve apartado a sintetizar y describir la natalidad empresarial de Ciudad Obregón entre 1925 y 1960.

${ }^{51}$ Numerosos antecedentes se mencionan en Martín et al., Registro, 2003. Cataluña ha sido uno de los casos analizados y difundidos en el contexto de la Europa meridional y de la América ibérica. Por ejemplo, Maluquer, "Demografía", 2001, y "Cataluña", 2001. Para Monterrey entre 1885 y 1930, Cerutti, "Fertilidad", 2004.

${ }^{52}$ Entre otros, los siguientes: ¿Toda región o toda ciudad presentan similar "fertilidad" empresarial? ¿Si hay diferencias, a qué factores se debe? ¿Es posible que dicha fertilidad se prolongue durante décadas o se transforme en un componente secular (lo que habría sucedido en los alrededores semiurbanos de Barcelona y en la Terza ltalia)? Como acaece con los seres humanos, ¿hay coyunturas más propicias para el nacimiento de empresas? ¿Existen coyunturas más riesgosas o poco favorables a la procreación de estas organizaciones? ¿Por qué en ciertas regiones, ciudades o economías el ritmo de crecimiento de las empresas es más limicado que el que se presenta en otras latitudes?
Un registro no exhaustivo ${ }^{53}$ efectuado en libros de notarios del periodo 1925 1955 arrojó lo siguiente: fueron constituidas (nacieron) al menos 315 empresas. Su evolución por quinquenio queda plasmada en el cuadro 10 y en las gráficas 6 y 7 , que detallan que los lustros más fértiles fueron los comprendidos en los años treinta.

Las escrituras revisadas muestran cómo se incrementó el número de registros empresariales en plena gran depresión y en vísperas de la segunda guerra, en una dinámica coyuntural que también hemos encontrado en Monterrey. Asimismo insinúan que existía una notoria actividad al final de los veinte, lo que coincidiría con lo sucedido en torno a Los Mochis y a la ya mencionada primera edad de oro del tomate. No ha quedado aclarado, sin embargo, cuál es el motivo del descenso de la fertilidad empresarial a partir de 1945, punto que habrá que resolver con más investigación.

Si por otro lado se procura diferenciar las empresas dedicadas a la agricultura y las agroindustriales del resto (comerciales, de servicios, financieras, industriales no transformadoras de materias primas rurales), el cuadro 10 y la gráfica 8 destacan cómo aquéllas resultaron fundamentales en la natalidad local hasta mediados de los cuarenta. Entre 1930 y 1944 llegaron a representar bastante más de $50 \%$ de las empresas nacidas en el territorio que tenía a Ciudad Obregón como referencia urbana, mientras que en todo el periodo incluyeron alrededor de $40 \%$ de las empresas fundadas (véase gráfica 9).

${ }^{53} \mathrm{Y}$ muy provisional, pues es menester procurar más fuentes notariales y revisar la sistematización inicial. 


\section{SECUENCIA}

Cuadro 10. Fertilidad por quinquenios (1925-1954)

Quinquenio

$1925 / 1929$

1930/1934

$1935 / 1939$

$1940 / 1944$

$1945 / 1949$

$1950 / 1954$

1925-1954
Nacidas (1)

54

70

76

56

36

23

315
Agricolaslagroindustriales(2)

16
38
38
32
3
2
128

Porcentaje 2/1

29.63

54.28

50.00

57.14

8.33

4.35

40.63

Gráfica 6. Natalidad por quinquenios (1925-1954)

\section{Empresa}

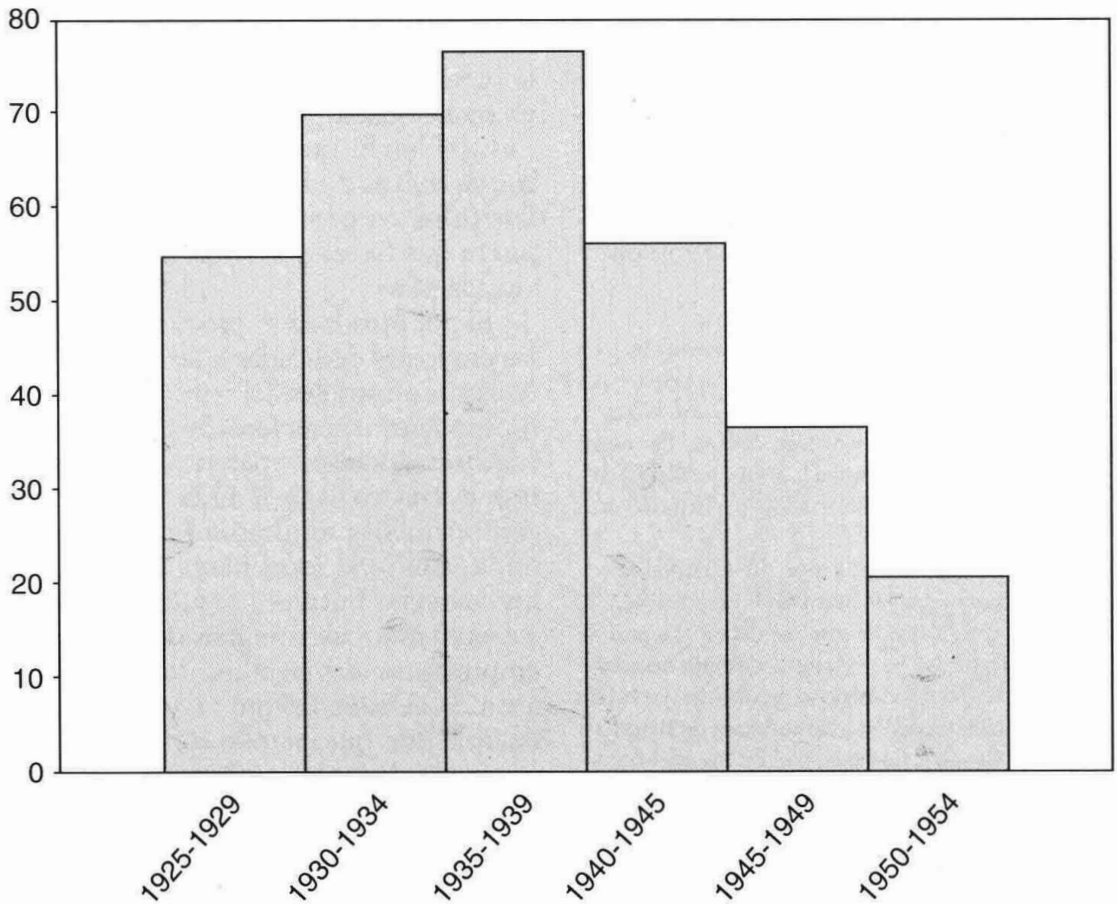

Fuentes: AGES, Libros de notarios (1925-1960) y AGNES. 


\section{Empresas}

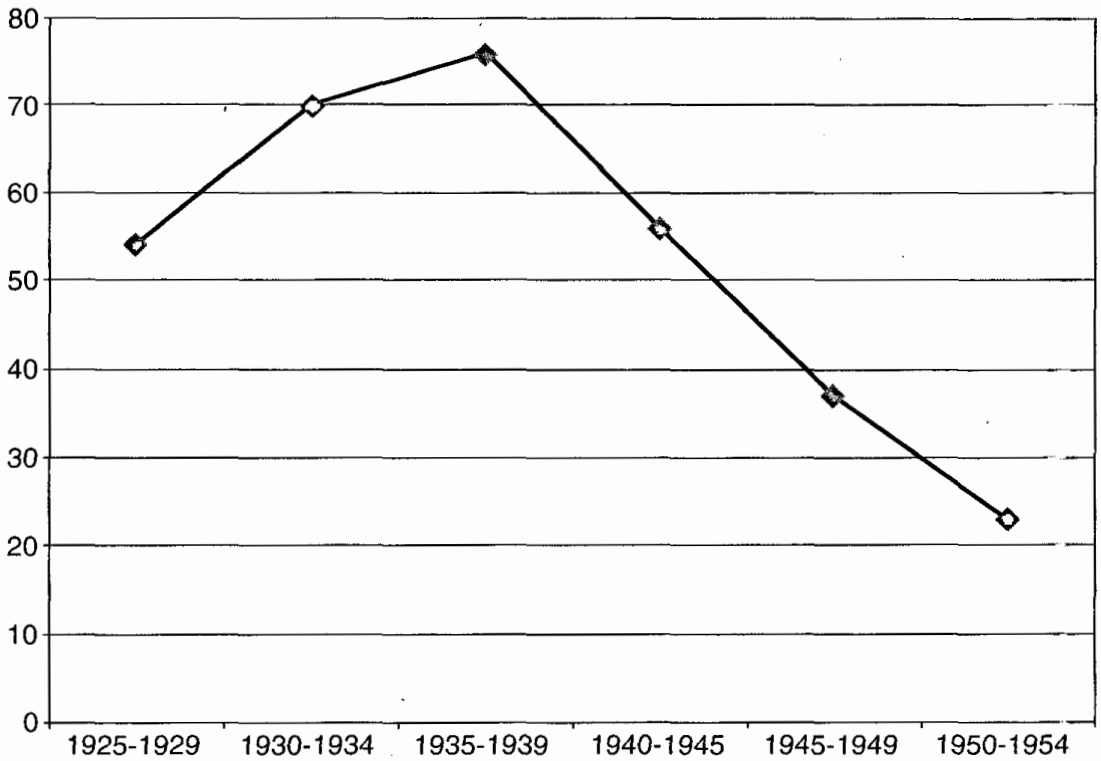

Fuentes: AGES, Libros de notarios (1925-1960) y AGNES.

La natalidad de empresas agrícolas fue decreciendo paulatinamente, tal vez porque, como acaeció en la vecina Sinaloa, muchos capitales acumulados en el sector rural fueron reinvertidos en sociedades cada vez más fuertes o transferidos a actividades urbanas: servicios y comercio, sobre todo.

Ello correspondería, por otro lado, con el crecimiento económico, demográfico, institucional y sociopolítico de Ciudad Obregón. Así, y en tanto el valle del Yaqui en su conjunto era considerado a principios de la década de los sesenta "un gran productor de materias primas alimenti- cias e industriales", ${ }^{4}$ Ciudad Obregón desbordaba los 60000 habitantes. La agrociudad había sido construida.

\section{LA CIUDAD DEL AGRO}

Según resume Rocío Guadarrama, la puesta en funcionamiento de la presa de Oviachic, a mediados de los cincuenta, se tornó

${ }^{5.4}$ Con 250000 toneladas de trigo, 150000 de algodón en pluma y 50000 de maíz. Dabdoud, IIistoria, 1995 , p. 383. 
Gráfica 8. Natalidad comparada por quinquenios (1925-1954)

\section{Empresas}

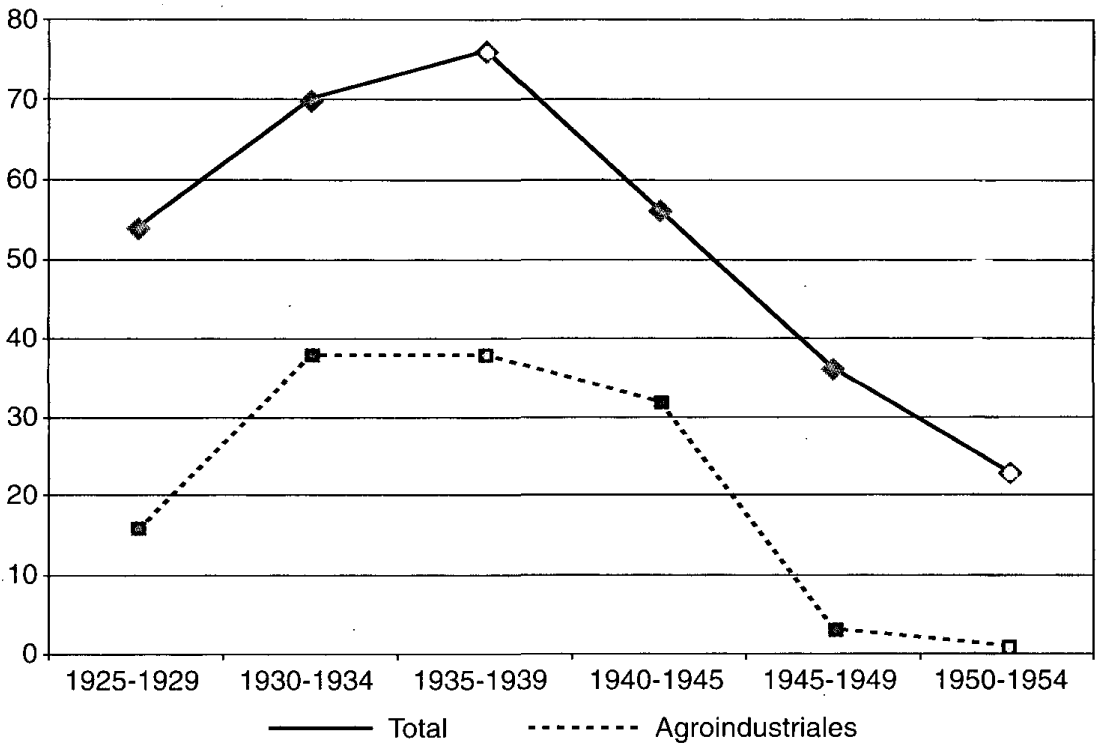

Fuentes: AGES, Libros de notarios (1925-1960) y AGNES.

un factor que "cambiaría radicalmente la vida de los habitantes del valle". Los agricultores más afortunados, que de paso concentraban el mayor número de hectáreas y agua, "se fueron a vivir a Ciudad Obregón". Entre otros motivos porque "en Pueblo Yaqui y en los campos aledaños no había luz ni agua potable y las casas eran de malos materiales".

En la cada vez más centralizante ciudad cabecera, en cambio, "los servicios eran mejores, había escuelas (hasta la secundaria) y las casas eran amplias y soleadas". 55

\footnotetext{
${ }^{55}$ Guadarrama, Empresarios, 2001, p. 130.
}

Y en un vivo retrato de la atracción que ya ejercía y de las funciones que cumplía el ascendente nudo urbano sobre los pobladores de su entorno, escribe:

Para los hijos de aquellas familias de nuevos agricultores, la ciudad no era totalmente desconocida, pues frecuentemente acompañaban a sus padres a realizar trámites oficiales y negocios o, simplemente, abastecerse de los implementos necesarios para el trabajo y la vida doméstica. Otros se habían ido desde antes a la ciudad a estudiar la secundaria (y) allí vivían en casas de parientes que les daban alojamiento. Para todos ellos, la 


\section{SECUENCIA}

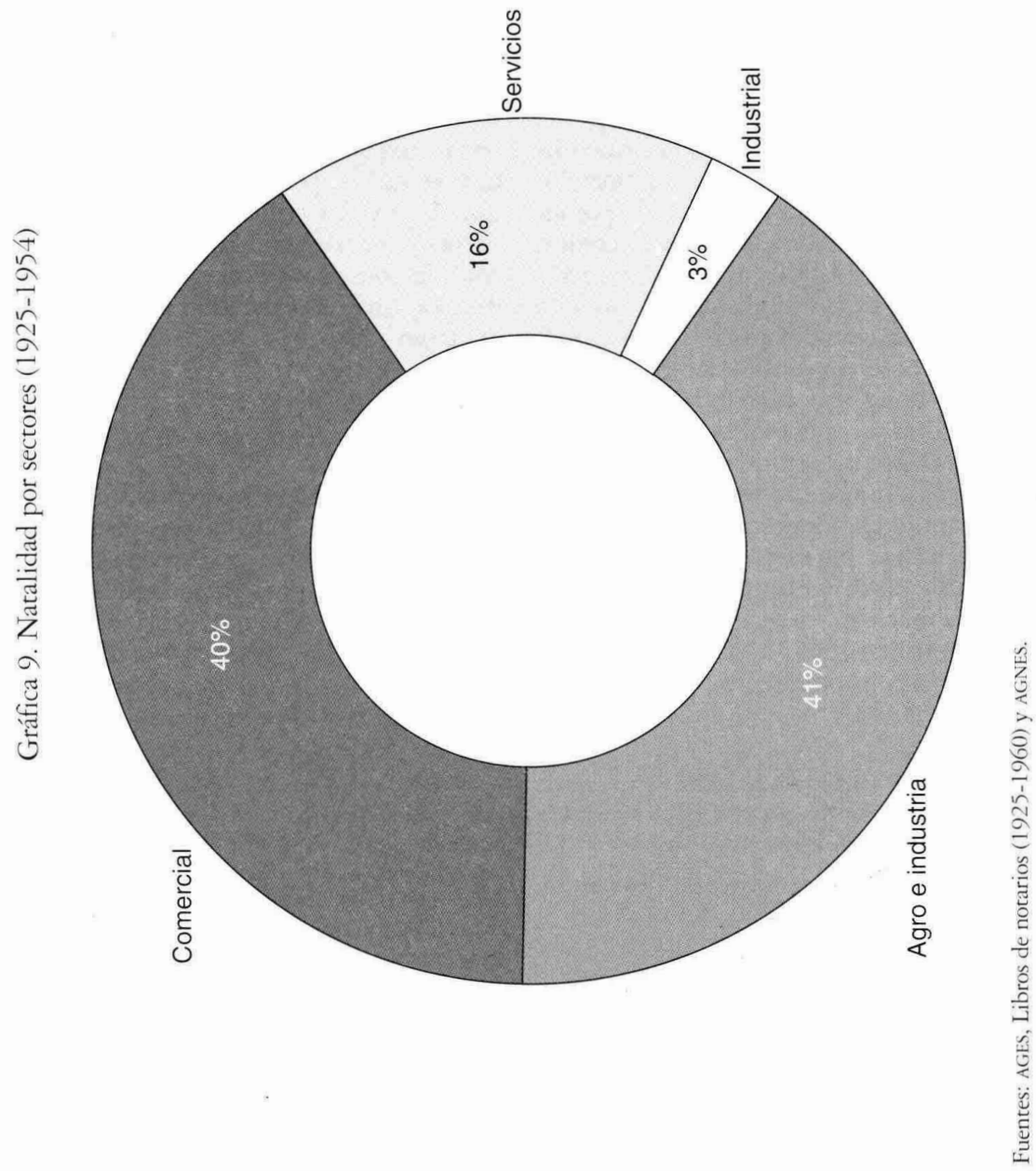


escuela sería una especie de filtro a través del cual sus experiencias campiranas y citadinas cobrarían un nuevo sentido.

Y más adelante, al explicar la llegada a Obregón de "una extensa capa de contadores, agentes comisionistas y comerciantes" que arribaban "atraídos por el auge agrícola de la región", Guadarrama detalla que la mayoría de estos inmigrantes ${ }^{56}$ "se colocó con éxito en los establecimientos comerciales y en los servicios relacionados con la agricultura", así como en despachos de abogados, la banca, uniones de crédito y demás actividades que tenían que ver con una ciudad en condiciones de atender con eficacia a tan dinámico entorno rural.

La progresiva centralidad regional de Ciudad Obregón se manifestaba asimismo en las comunicaciones. Por un lado, el ferrocarril, instalado en tiempos porfirianos. Por otro, la red de carreteras y caminos que se extendieron desdé los años cuarenta, a lo que habría que sumar la siempre aprovechable cercanía de Guaymas para el tráfico marítimo y la inauguración del aeropuerto en 1961 (año en que "el proceso de expansión del área cultivable del

${ }^{56}$ El propio municipio de Cajeme nunca dejó de aumentar su población a partir de 1930 , y en términos relativos frente a Sonora creció hasta 1990:

\begin{tabular}{lrrc} 
Año & \multicolumn{1}{c}{ Cajeme } & Sonora & Cajeme/Sonora \\
1930 & 12000 & & \\
1940 & 27519 & & \\
1950 & 63025 & 510607 & 12.34 \\
1960 & 124162 & 783378 & 15.85 \\
1970 & 182904 & 1098720 & 16.65 \\
1980 & 255845 & 1513731 & 16.90 \\
1990 & 311443 & 1823606 & 17.08 \\
1995 & 345222 & 2085536 & 16.55 \\
2000 & 356290 & 2216969 & 16.07
\end{tabular}

Yaqui" había quedado definido en su totalidad, con más de 250000 hectáreas). ${ }^{57}$

No debe olvidarse además el impacto local de la fundación, en 1955, del Centro de Investigaciones Agrícolas del Noroeste (CIANO), verdadero pionero en el México norteño en materia de vinculación entre instituciones gubernamentales, investigación científica y sectores productivos. ${ }^{58}$ Estuvo en el medio y fue sustento de la revolución agrícola que se desató en el sur de Sonora: "la aportación más importante que el CIANO ha hecho a la agricultura del noroeste, en sus primeros 25 años de trabajo, lo constituye la tecnología de producción que ha generado para el cultivo del trigo". 59

\section{RECUENTO}

1. El valle del Yaqui pasó de ser un área bajo el oscilante dominio de culturas locales a un territorio sometido al control del capital. Este proceso, inaugurado durante el porfiriato, se intensificó desde los años veinte del siglo $\mathrm{xx}$ y coronó cuando se construyeron las grandes obras de irrigación del Estado posrevolucionario.

57 Dabdoud, Historia, 1995, pp. 371.73.

58 "Para impulsar la investigación y apoyar el desarrollo agrícola del noroeste del país se fundó en 1955 el Centro de Investigaciones Agrícolas del Noroeste" (CIANO), en un terreno de 100 hectáreas (manzana 810) con el auspicio y patrocinio de ayricultores sonorenses y apoyo del gobierno federal." Vargas, $D e-$ predadores, 2003 , p. 219. Se le sumarían posteriormente el Instituto Tecnológico de Sonora (ITSON) y, ya en los setenta, el campus Ciudad Obregón del Instituto Tecnológico y de Estudios Superiores de Monterrey (ITESM), segunda unidad en México.

59 Vargas, Valle, 2004, p. 222. Sobre sus antecedentes, véase también Hewitt, Modernización, 1999. 
La agriculturización del territorio que inicialmente colonizaron Carlos Conant y la Constructora Richardson supuso la aparición de un variado racimo de productores (mexicanos e inmigrantes) cuya dinámica no cesó con la reforma agraria de los años treinta. De manera similar a lo sucedido en La Laguna desde 1870, lo que sería el entorno de Ciudad Obregón se convirtió en un vivaz tejido productivo sustentado en la agricultura que, a la vez, generó uno de los múltiples bolsones empresariales que han aparecido en el norte en los últimos 150 años.

3. El nacimiento y desarrollo de Ciudad Obregón, en el sur de Sonora, dependió en fuerte proporción de ese contexto. Poco a poco la cabecera del municipio de Cajeme fue asumiendo relevancia dentro de la red de pequeñas urbes que se situaban entre Guaymas y Guasave, y se transformó también en la más importante ciudad entre Hermosillo y Culiacán.

4. Dentro del espacio biestatal analizado, de todos modos, no había dejado de afirmarse

un denso tejido de ciudades medias y pequeñas que aseguran la provisión de servicios a las empresas y la existencia de equipamientos educativos, asistenciales, financieros suficientes para un funcionamiento eficaz. ${ }^{60}$

5. Ciudad Obregón acompañó ese mecanismo, pero el vigoroso y creciente entrecruzamiento de agricultura e industria de transformación, los sistemas de transporte vial y ferroviario, el emerger de un firme componente comercial y de servicios, los apoyos institucionales, y una mayor atracción migratoria la definieron a

${ }^{60}$ Méndez, "Sistemas", 1994, p. 100. mediados del siglo xx como una auténtica agrociudad. Es decir: como un núcleo urbano nacido de la agriculturización del territorio que la rodea, y sobre el cual comienza a ejercer paulatinamente una centralidad funcional.

\section{ArCHIVOS}

AGES Archivo General del Estado de Sonora. AGNES Archivo General de Notarías del Estado de Sonora.

\section{Bibliografía}

- Aguilar Aguilar, Gustavo, Banca y desarrollo regional en Sinaloa (1910-1994), Plaza y Valdés/ Universidad Autónoma de Sinaloa, México, 2001.

-Araiza Noriega, Patricia, "Los molineros, los molinos y la harina en el estado de Sonora durante el porfiriato (1880-1.910)", tesis de licenciatura, Universidad de Sonora, 1997.

-Bagnasco, Arnaldo, "Nacimiento y transformación de los distritos industriales" en Marcello Carmagnani y Gustavo Giordillo de Anda (coord.), Desarrollo social y cambios productivos en el mundo rural europeo contemporáneo, FCE/COLMEX, México, 2000.

-Becattini, Giacomo, Marshall. Antología di scritti economici, Il Mulino, Boloña, 1981. , "Anomalías marshallianas" en (iiacomo Becattini y otros, Desarrollo local: teorias y estrategias, Biblioteca Civitas Economía i Empresa/Diputació Barcelona, Madrid, 2002.

Cartón de Grammont, Hubert, Los empresarios agrícolas y el Estado, UNAM, México, 1990.

Cerutti, Mario, "Fertilidad empresarial en Monterrey (1885-1930)", Estudos do Século Xx, núm. 4, 2004, Universidad de Coimbra.

, "Redes y bolsones empresariales en el norte de México (1870-1920)", ponencia pre- 
sentada en el VII Congreso de Historia Económica de España, Santiago de Compostela, septiembre, 2005.

-Dabdoud, Claudio, Historia de el valle del Yaqui, Gobierno del Estado de Sonora, Hermosillo, 1964 (edición facsimilar, 1995).

-Díaz Coutiño, Reynol, Sinaloa. Riqueza y pobreza de agza, Universidad Autónoma de Sinaloa, Culiacán, 2005.

-Frías Sarmiento, Eduardo, "La agricultura de exportación en Sinaloa", tesis doctoral en curso.

-Fujigaki Cruz, Esperanza, Modernización agricola y rovolución. Haciendas y compañias agricolas de irrigación del norte de México, 1910-1929, UNAM, México, 2001.

-Garza, Gustavo y Jaime Sobrino, Industrialización periférica en el sistema de ciudades de Sinaloa, Colmex, México, 1989.

-Gill, Mario, La conquista del valle del Fuerte, Universidad Autónoma de Sinaloa, Culiacán, 1983.

-Gorenstein, Silvia, "Rasgos territoriales en los cambios del sistema agroalimentario pampeano (Argentina)", Revista de Estudios Regionales, Universidades de Andalucía, núm. 61, septiembre-diciembre, 2001.

-Gracida Romo, Juan José, La llegada de la modernización a Sonora. Establecimiento del ferrocarril (1880-1897), Universidad de Sonora, Hermosillo, 2001.

_._. "E1 Ferrocarril del Sud Pacífico de México, 1909-1910. Especialización productiva y efectos" en Memoria, XIV Congreso Nacional de Historia Regional, Culiacán, 2002.

, "El ferrocarril y su importancia en el desarrollo agrícola del valle del Mayo", III Seminario Empresa y Agricultura de Exportación, Monterrey, noviembre de 2003.

"El papel del transporte en la dinámica empresarial de los valles del Yaqui y del Mayo (1925-1960)", 2004, mimeo.

_-_ "Impacto de la revolución mexicana en Sonora, 1910-1920" en José Mario Con- treras Valdés et al., Actividades, espacios e instituciones económicas durante la revolución mexicana, UNAM, México, 2004.

-Guadarrama Olivera, Rocío, Las empresarios norteños en la sociedad y la política del México moderno. Sonora (1919-1988), varios editores, México, 2001.

-Hernández Moreno, María del Carmen, Crisis avícola en Sonora. El fin de un paradigma, 1970-1999, Universidad Autónoma de Sinaloa/ Universidad de Sonora, México, 2001.

-Hewitt de Alcántara, Cynthia, La modernización de la agricultura mexicana, 1940-1970, $\mathrm{Si}-$ glo XXI, México, 1999.

- Historia general de Sonora, Gobierno del Estado de Sonora, Hermosillo, 1985, t. v.

-López Ontiveros, Antonio, "La agrociudad andaluza: caracterización, estructura, problemática", Revista de Estudios Regionales, núm. 39, mayo-agosto, 1994.

-Lorenzana Durán, Gustavo, “Compañías agrícolas, concesiones de agua y obras hidráulicas, 1900-1910" en XI Encuentro de Historia Económica del Norte de México, Hermosillo, octubre-noviembre, 2002.

" "Obras hidráulicas en los valles del

Yaqui y del Mayo. De la iniciativa individual a la participación federal (1888-1992)", ponencia presentada en III Seminario Empresa y Agriculrura de Exportación, Monterrey, noviembre de 2004. , "El avance de la frontera agrícola en el sur de Sonora (1880-1941)", ponencia presentada en el IV Seminario sobre Empresa y Agricultura de Exportación en el Noroeste", Mazatlán, junio.

-Los municipios de Sonora, s. p. i, Hermosillo, s. a.

-Maillat, Denis, "Sistemas productivos regionales y entornos innovadores" en Charles Sabel et al., Redes de empresas y desarrollo local, OCDE, París, 1996.

-Maluquer de Motes, Jordi, "Cataluña, avanzada de la industrialización" en Luis Germán y 


\section{SECUENCIG}

otros (eds.), Historia económica regional de España. Siglos XIX y XX, Barcelona, Crítica, 2001.

"La demografía empresarial como instrumento de la historia económica. Algunos ejemplos de la Europa del sur en los siglos XIX y xx", Segundo Seminario Nacional sobre Empresas y Empresarios del Centro y Norte de México. Siglos XIX y XX, Mazatlán, mayo de 2001.

-Marshall, Alfred, Principios de economía, Aguilar, Madrid, 1957.

-Martín Rodríguez, Manuel et al., El Registro Mercantil: una fuente para la bistoria económica, Universidad de Granada, Granada, 2003.

-Méndez Gutiérrez del Valle, Ricardo, "Sistemas productivos locales y políticas de desarrollo rural", Revista de Estudios Regionales, núm. 39, mayo-agosto, 1994.

-Oñate, Abdiel, Banqueros y hacendados. La quimera de la modernización, UAM, México, 1991.

Ortega Leite, Octavio, "Datos de la explotación agrícola del valle del Yaqui, Sonora", Irrigadora del Yaqui, S.A., Ciudad Obregón, s. a., mimeo.
-Romero Ibarra, María Eugenia, “Azúcar y empresa. La United Sugar Companies, S. A. (1890-1.950)", 2003, mimeo.

—_ - "El desarrollo empresarial en el noroeste de México. Los orígenes (1880-1930)", México, 2005, mimeo.

-Santillán Domínguez, Everardo, "Ia Cámara Agrícola y Comercial del Río Mayo, 1921 1932 ", tesis de licenciatura, Universidad de Sonora, 1998.

-Vargas Martínez, Alberto, Los depredadores. Testimonio de la expropiación agraria en el Valle del Yaqui en 1975-76, s. p. i., Ciudad Obregón, 2003.

riego, s. p. i., Guadalajara, 2004.

- Verduzco, Gustavo, Una ciudad agricola: $Z a-$ mora. Del porfiriato a la agricultura de exportación, Colmex/El Colegio de Michoacán, México, 1992. 